\title{
Sourcing decision under interconnected risks: an application of mean-variance preferences approach
}

\author{
Soumyatanu Mukherjee ${ }^{1,2,3}$ (D) $\cdot$ Sidhartha S. Padhi ${ }^{4}$
}

Accepted: 6 December 2021 / Published online: 6 January 2022

(c) The Author(s) 2022

\begin{abstract}
Supply chains are customarily associated with multiple interconnected risks originated from supply side, demand side, or from the unanticipated background uncertainties faced by a firm. Also, effective functioning of supply chain hinges on sourcing decisions of inputs (raw materials). Therefore, there is a striking need to analyse the risk preference of the decision maker while going for optimal sourcing decision under varying degree of interconnected supply chain risks. This study addresses this issue by analysing the comparative static effects under interconnected supply chain risks for a risk averse decision-maker, manufacturing and selling products in a regulated market under perfect competition. The decision-maker faces not only supply-side risk (due to random input material prices) but also interconnected risks arising out of background risk (setup costs risk) and demand-side risk (output prices risk). With preferences defined over the mean and standard deviation of the uncertain final profit, this study illustrates the effects of the changes in the pairwise correlations between the three above mentioned risks on the optimum input choice of the manufacturer. To contextualise this study, an India-based generic drug manufacturer cum seller has been considered as a case in the parametric example of our model. Adaptation of the mean-variance framework helps obtaining all the results in terms of the relative trade-off between risk and return, with simple yet intuitive interpretations.
\end{abstract}

Keywords Supply chain risk · Interconnected risks · Decision analysis · Sourcing decision · Mean-variance model

$凶$ Soumyatanu Mukherjee

S.Mukherjee@soton.ac.uk

Sidhartha S. Padhi

sidhartha@iimk.ac.in; drpadhi@gmail.com

1 Department of Banking \& Finance, Southampton Business School, University of Southampton, 2/4051, Highfield, Southampton SO17 1BJ, Hampshire, UK

2 Associate External Fellow, CREDIT and GEP, University of Nottingham, Nottingham NG7 2RD, England, UK

3 Ural Federal University, Yekaterinburg, Russia

4 Faculty of Quantitative Methods and Operations Management Academic Hill, Indian Institute of Management, Room \# 16, Block C, Kozhikode, Kerala 673570, India 


\section{Introduction}

Supply Chains (SCs) of firms are intrinsically pregnable to risk. While involvement of multiple supply chain components has added to the complexity of SCs over the years, the practitioners and academicians witness intense SC incidences due to interconnected nature of components in SC (Sheffi, 2007; Waters, 2011). Although interconnectedness has been long understood, researchers have not yet arrived at a holistic understanding of the concept that connects the supply chain risk components (Harland, 2021) i.e., interconnected risk structure in which actions taken to resolve one risk affects other dependent risks. The summative intensity of disastrous events due to interconnected components affecting SCs by far exceeds that of the significant natural hazards like the Japanese Tsunami or the US hurricane Katrina. Therefore, there is a need to arrive at a connected and integrated perspective to the phenomenon. Especially in case of sourcing decision of a firm where an array of SC risks (see for example, Peck, 2006; Wagner \& Bode, 2006; Pettit et al., 2013; Ho et al., 2015) and associated interconnectivity among the different risk sources add to the complexity (Kayis and Karningsih, 2012). We cite below a few examples of interconnected risks related challenges faced by firms.

The interconnection between dollar value and sales of cars leads to Volvo's loss of revenue, which affected its raw material sourcing decisions. Similarly, disruption in chip supply and sourcing issue leads to Ericsson's USD 0.4 billion losses (Tang \& Musa, 2011). Part of the reason for Toyota's product recall crisis is due to SC complexity that emerges from interconnected supply components (Bode \& Wagner, 2015). Chevron corporations, one of the largest oil company of the USA, witnessed production shutdown followed by a loss of 400 million USD owing to natural disasters. The hurricanes, Gustav and Ike in the Gulf of Mexico adversely affected the oil production subsequently leading to rise in crude oil price in the region (Wagner et al., 2014). In 2009, over 670,000 suppliers in China closed their doors due to interconnected SC risks like uncertain demand, late payments, and restricted credit markets (Liu \& Cruz, 2012). The rapid growth of Cisco Systems, Inc. was fuelled by an outsourcing strategy that significantly increased the interconnectedness and SC complexity. However, the capacity of Cisco Systems, Inc. to organise its SC and responding to a quickly evolving telecommunication market was eventually overwhelmed by the SC complexity. As a result, when the market crashed in early 2000, Cisco Systems, Inc. was unable to adjust, resulting in a $300 \%$ increase in inventory a $\$ 2.25$ billion write-down (Hearnshaw \& Wilson, 2013). Hence, interconnected SC risks must be considered by firms as seriously as any other business risk while developing a sourcing plan (Elkins et al., 2005; Heckmann et al., 2015; Wagner \& Bode, 2009). Notably, focusing on the strength of this interconnectedness among risk sources - tightly and (or) loosely coupled - could help in developing sourcing plans critical to SC risks (Guertler \& Spinler, 2015; Liu \& Cruz, 2012; McNerney et al., 2011; Skilton \& Robinson, 2009).

Analysis of interconnected risks helps in understanding of complex interactions in a system that could be integrated into decision making process (Pescaroli \& Alexander, 2018). Interconnectivity in a system has been addressed in the literature using two broad perspectives i.e., dependency structure of risks and decision-making under interconnected risks. A recent review by Pournader et al. (2020) suggested that uncertainty within the SC network has been addressed using expected utility approach considering newsvendor's decision problems (e.g., Kazaz \& Webster, 2015; Li and Ki, 2021). On the other hand, studies have explored the dependency structure of risks using complex adaptive system (Phillips \& Ritala, 2019; 
Sweetman \& Conboy, 2018) and complex network (Skilton \& Robinson, 2009; Giannoccaro and Iftikhar, 2020). Of which, complex network is becoming more popular because it can assist in understanding the underlying dependency structure of SC systems (Pournader et al., 2020). Therefore, understanding the dependency structure can better assist the decision maker to arrive at optimal solutions to a number of SC network problems (Bombelli et al., 2020; Hearnshaw \& Wilson, 2013), especially sourcing decision where sources of risks are interconnected (Wagner et al., 2014). But the uncertainties arising out of the varying degrees of interconnectedness among different sources of risks in a complex SC network and the optimal sourcing decision have been recognised as the most challenging task (Govindan et al., 2017; Shen, 2013).

To arrive at an optimal sourcing decision, it is essential for a decision maker to understand multiple sources of risks, where categorization of these sources of risks could help to gain better understanding about the dependency structure. In this regard, Supply Chain Risk Management Council (2011) has categorised SC risks into two types i.e., internal- and external- disruption risks. Subsequently, another class of literature (e.g., Christopher \& Peck, 2004) described SC risks as internal to the firm (i.e., risks related to process of setting up an operational activity and setup cost risk), and external to the firm but internal to the supply chain network (i.e., supply and demand-side risks). Following this we have categorized the sources of risks into three types: viz., demand side risks, supply side risks, and background risks. Considering these three types of risks, several authors (e.g., Kumbhakar \& Tsionas, 2010; Rodríguez-Puerta \& Álvarez-López, 2016) have evaluated the optimal choice of a decision maker in the presence of either demand- or supply-side risks. For instance, Kumbhakar and Tsionas (2010) considered von Neumann-Morgenstern (hereafter vNM) expected utility (hereafter EU) approach to analyse only supply-side risk for a risk averse manufacturer. Rodríguez-Puerta and Álvarez-López (2016), on the other hand, in an EU framework, have considered only demand-side risk to decide optimal production allocation of a fixed amount of output to the two possible destinations: one with certain price and another with uncertain price. However, due to the inherent complexity of the classical EU models, it is almost impossible to analyse the implications of changes in dependence structure or interconnectedness among multiple risks on the risk preference pattern driving the optimal sourcing decision within a SC network system.

Notably, the literature is strikingly silent about the risk preference of the decision maker, while going for optimal sourcing decision, with respect to varying degrees of interconnectivity-tightly (or loosely) coupled — among different sources of risks, viz., supply-side risks, demand-side risks, and background risks. Especially, in the case of a risk averse manufacturer where the optimal level of sourcing (or input choice) varies with change in the interconnectedness (Fischl et al., 2014) between the background risks and the supply-side risks under a regulated market condition, which has not been investigated in the literature till date. Moreover, when the demand-side risks arise out of varying government policies in a decentralised market condition, the change in interconnectedness between the demand-side risks and background risk also lack substantial investigation in terms of the risk-taking behaviour of the manufacturer. This glaring question has also not been addressed in the extant literature so far. ${ }^{1}$ Thus, to address the above research gap, this paper aims to answer the following questions:

- What will be the optimal sourcing decision under varying degree of interconnectedness between the supply side (input price) and background risks, ceteris paribus?

1 This usually involves a reduction in price-support measures, which may, in turn, alter the price distribution. Our model allows for price variability, and thus offers a better approximation of the context in which producers make decisions. 
- What will be the optimal sourcing decision under ceteris paribus changes in the degree of interconnectedness between the demand side (output price) and background risks?

- What will be the optimal sourcing decision under varying degree of interconnectedness between the demand side and the supply side (input price) risks, ceteris paribus?

To contextualise the above research questions, we have considered the decision problem of a perfectly competitive single-product manufacturer in a regulated environment. As an example of this class of decision-makers, we consider the context of a generic drug manufacturer of a pharmaceutical industry, wherein a representative firm operates in a perfectly competitive framework under regulated environment. However, it faces three sources of risks. The first is a price risk that results from the price volatility that the firm receives either from domestic sales or from foreign sales. The second is risk in input material costs. These two sources of risk are termed as 'endogenous risk', directly affecting the firm's final profit and optimal sourcing decision. However, there are other randomness that can also passively affect output by altering the set-up costs of production, for example, technical breakdowns, infrastructure, worker issues, policy and environmental regulations, and legal suits. These uncertainties are usually not diversifiable and can be termed as 'background risk'. In summary, this study analyses the sourcing decision of raw material for a risk averse generic drug manufacturer of India not only under randomness of supply-side risk (input prices) and background risk originated from supply-side (setup cost), but also under randomness in demand-side risk (output prices). All the risks mentioned above are interconnected hence the implications of varying interactions among them on the optimal sourcing decision are analysed.

To answer the three research questions mentioned above, we have used a two-moment (or equivalently, a mean-standard deviation) decision-theoretic approach (see, for example, Eichner \& Wagener, 2003, 2009, 2012; Alghalith et al., 2017; Broll \& Mukherjee, 2017; Broll et al., 2019; Padhi \& Mukherjee, 2021). In such decision-theoretic modelling approach, the preferences over random distributions of the objective function are represented by the utility function, which is defined over only the mean and the variance (or standard deviation) of the objective function. The key determinants for the properties of a risk averse manufacturer's preference towards uncertainties turn out to be the relative trade-off between risk and return (also known as "elasticity of risk aversion"). Irrespective of the multidimensional risks or choice variables such model continues to be two-dimensional. This approach facilitates direct modelling of such decision problem without assuming anything pertaining to the higher-order and cross-derivatives of the preference functional (while the latter would almost inevitably arise under the EU approach). Perhaps, this is the first study applying the two-moment decision model to the literature of interconnected SC risk within a SC network.

The paper further is structured as follows: A review of the relevant literature looks at interconnected risks in SC following the systems theory approach. Subsequently, it explains the methods to find the risk averse manufacturer's optimum input choice decision under interconnected risks followed by a numerical case of a generic drug manufacturer cum seller. Finally, a detailed simulation exercise is carried out to investigate the impact of mitigation measures on SC risks and illustrates the analytical and practical applications in the conclusion section. 


\section{Literature review}

When investigating risks and the impact of sourcing decisions on SCs, there are two areas of academic literature that support the research questions: (1) Sourcing decision under SC risks, and (2) Interconnected SC risks.

\subsection{Sourcing decision under SC risks}

SC Risk is an essential research domain in SC (Heckmann et al., 2015; Tang \& Musa, 2011; Thun \& Hoenig, 2011; Turner, 2011). As firms have to operate safely and in compliance with government regulations meeting targets for efficiency and effectiveness at the same time, the need to eliminate their exposure to uncertainties by managing the risks in the SC is also paramount. This includes the identification and assessment of anticipated risks as well as the materialization of appropriate sourcing decisions to steer and monitor them (Chopra \& Sodhi, 2004; Sodhi et al., 2012). Ho et al. (2015) reviewed 224 journal articles to provide a comprehensive list of risk factors and risk types. Majority of the papers have discussed endogenous (or internal) and exogenous (or external) risk types which is in line with the Supply Chain Risk Management Council (2011) categorization. Fahimnia et al. (2019) have classified SC risk literature into eight types which can further be deduced to three major types such as supply side, demand side, and background risks which is in line with the other researchers (e.g., Christopher \& Peck, 2004). Similarly, Jüttner et al. (2003) have also categorized risk sources into external and internal SC risks, and network related risks. Thus, following the above classification, this study investigates the SC risks in further details.

The supply-side risk arises because of poor logistics performance of suppliers; supplier quality issues; financially distressed supplier; insufficient supply capacity of supplier(s); and variability of replenishment lead time, etc. (Samvedi et al., 2013; Shekarian and Parast, 2020). According to Faisal (2009) Supply-side risks can influence input price risk of raw materials because of the interconnectedness of other sources of risks. Subsequently, background risk can include catastrophe, change in the government policies, and information mismatch (Faisal, 2009). Kumbhakar and Tsionas (2010) argued that input choices also affect variability of output (commonly termed as "production risk"). For example, uncertainties related to capacity utilization, inventory management, worker issues, infrastructure, etc. hence, might be augmenting as background risk. Background risk can influence the setup cost during the production. Finally, unanticipated demand, insufficient information from consumers regarding orders, unusual delay in the payment, market shifts, and forecasting errors are some of the factors that leads to demand side risks. These risks ultimately influence the firm's output price because of the potential gap between actual and expected demand, as well as potential disruptions in the flow of products and information within the supply network. Moreover, in competitive markets, extended operational lags are also often imposed by randomness in output prices (principally owing to the inelastic demands). This is because output prices are unknown when operational/manufacturing decisions are made. Such ex-ante operational decisions may thus differ from choices that would have been made had manufacturers known ex-post output prices. As a result, price uncertainty widens the gap between the anticipated ex-post profit and the profit that would have made under elastic demand and full information about the market regulations and industry-specific or fiscal policies are available. Models conversed about behaviour under output price uncertainty were examined by Sandmo (1971), Chung (1990), Rodríguez-Puerta and Álvarez-López (2016), Guo et al. (2021), among others. 
Each SC has its attributes and needs a specific set of measure. These measures must always adapt to the circumstances of a particular firm (Chopra \& Sodhi, 2004; Hendricks \& Singhal, 2005; Kleindorfer \& Saad, 2005; Ritchie \& Brindley, 2007). Otherwise, measures that mitigate one risk can end up exacerbating the other connected risks (Chopra \& Sodhi, 2004). Following the network system approach, we propose that the causes of uncertainty in any SC network are due to tightly or loosely interconnected network of these risks (Giannakis \& Papadopoulos, 2016).

The complexity of the network emerges from multiple arrays of interconnected risks primarily comprising of three types of risks as shown in Fig. 1. Thus, to analyse the optimal sourcing decision of raw material in the presence of three types of risks, we have used randomness of input prices, randomness in output prices, and randomness in setup cost as the surrogate measure for the supply side risk, the demand-side risk, and the background risk originated from supply-side, respectively. This interconnectedness among each of the risks independently and in cohesion follow multivariate normality, hence these risks can linearly interact with the decision variable.

Notably, in the literature the most popular analytical approaches to analyse interconnected SC risks are mixed integer linear programming, followed by EU based newsvendor model and simulation approaches (Ho et al., 2015). However, the significant gap in the extant literature is the absence of interconnected risks' assessment and optimal sourcing decision. Although a few studies (e.g., Hachicha \& Elmsalmi, 2014; Venkatesh et al., 2015) have applied structural modelling technique to identify risk inter-connectedness the extant literature that is still limited to empirically modelling responses to interconnected risks in SC (Faisal, 2009). However, literature is silent towards the optimal decision choice of the risk averse behaviour of a manufacturer. Where the manufacturer experiences multiple interconnected risks when sourcing input raw materials from a supplier to manufacture a generic product and subsequently selling the product in a price-regulated market (Fischl et al., 2014). The aim is to identify the potential risks and propose sourcing decisions that can reduce the expected risk (Hong \& Lee, 2013) for a risk averse manufacturer.

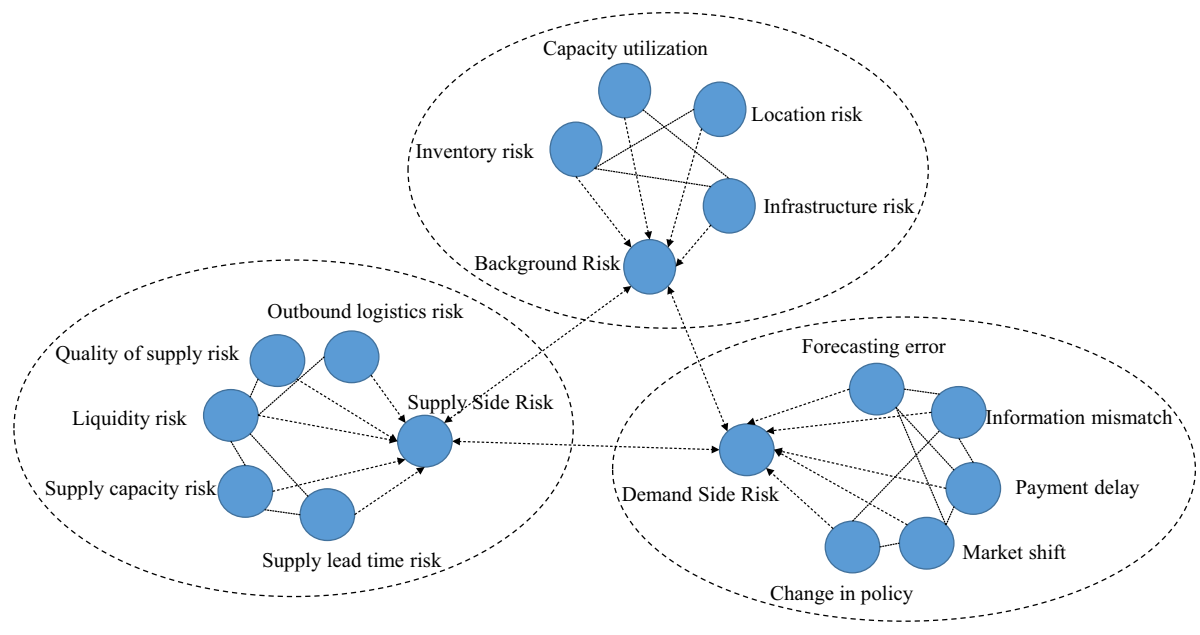

Fig. 1 Complex network of supply chain risks 


\subsection{Interconnected SC risks}

In general, risks are interconnected (Bluhm \& Krahnen, 2014; Correa-Henao et al., 2013). As an illustration, managers face multiple risks depending on their relative stance. A financially distressed supplier holds the risk of getting bankrupt, but at the same time, it may also cause stock-outs or deliver inferior product in terms of quality. Similarly, natural disasters can affect not only the operation of a firm but also the operation of its suppliers and third-party logistics providers. Subsequently, impact and the required recovery time will be much higher than that forecasted for the firm itself. Hence, it reveals the need for models to take inter-connectivity of risks into account. Such a perspective has to go beyond adding losses, delays, or similar performance indicators for each potential risk. According to network theory, relatively localised damage in one system may lead to failure in another, generating a disruptive avalanche of cascading and increasing impact on the entire SC network (Vespignani, 2010). Complexity of SC-risk inter-connectivity is the degree of the interdependency of risks occurring at the same level or different levels of a SC as shown in Fig. 2. Risks, even at the same level of a $\mathrm{SC}$, are correlated; for instance, supplier default risk can be connected with supplier quality risk or supplier capacity risk.

The interconnectedness of SC risks has increased the complexity and uncertainty levels of any supply chain (Mizgier et al., 2013). To assess interconnected SC network risks Ledwoch et al. (2016) have applied Katz centrality, hub centralities, and betweenness centrality metrics to the systemic risk concept. Wagner et al. (2014) have used numerical simulations on tightly coupled exogenous SC risks to develop a decision support system. Subsequently, Ivanov (2018) have used a simulation approach to mitigate the ripple effect and increase the sustainability of an interconnected SC. Earnest and Wilkinson (2018) have used an agent-based simulation using Kauffman's NK models to study performance of a SC network. Furthermore, authors have studied interconnected risks using multi-risk assessment models like

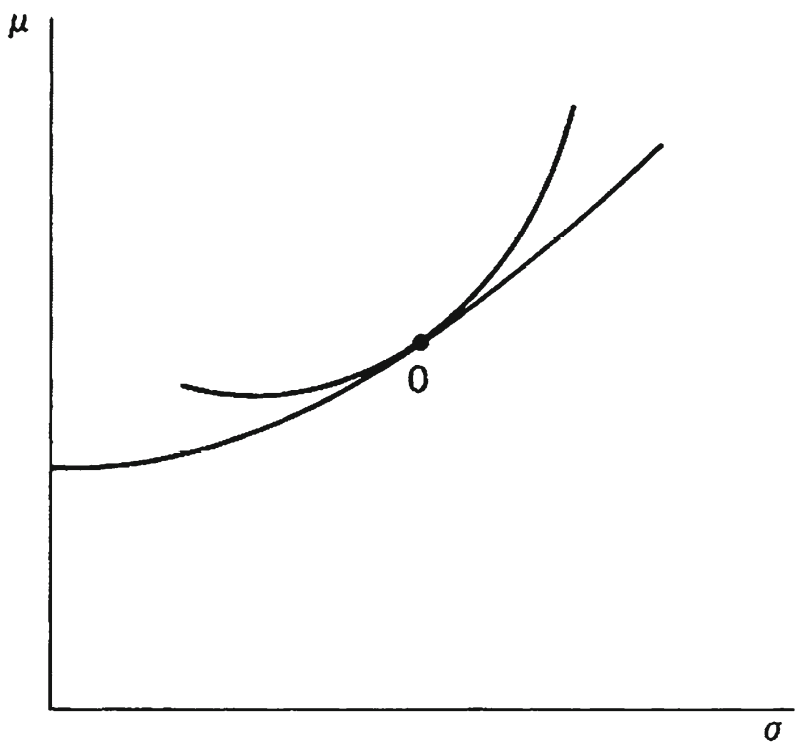

Fig. 2 The first order condition (F.O.C.) 
elementary bricks model (Zuccaro et al., 2018), design structure matrix (Baldwin and Clark, 2000), RiskRank as a hierarchical network (Mezei \& Sarlin, 2018), causal network model (Cavallo \& Ireland, 2014), Structural Equation Model (Shahbaz et al., 2020). These studies have focused only on the dependence structure or interconnectivity among different types of risks to understand the complexity of a SC system through analyzing the transmission of risks in a system. Starting points for interconnected risks along the SC can be found in the literature on risk correlations (Han \& Huang, 2007; Wallace et al., 2004) or copula functions (Babich et al., 2007; Wagner et al., 2009). Rodríguez-Puerta and Álvarez-López (2016) have considered supply side risks (output price and production quantity) to decide optimal production allocation. However, literature is silent about the behavior of the decision maker and his optimal choices with respect to varying degrees of interconnectivity among three different sources of risks. Therefore, this paper focuses on modelling the attitude of a risk averse manufacturer to obtain optimal supply decision under tightly versus loosely interconnected risks utilising the two-moment (i.e., mean-standard deviation) decision theoretic approach. This modelling approach has also been applied by Eichner \& Wagener, 2003, 2009; Alghalith et al., 2017; Broll \& Mukherjee, 2017; Broll et al., 2019; Huang \& Jiang, 2020; Padhi \& Mukherjee, 2021; among a few of the many. In such decision-theoretic modelling approach, the preferences over random distributions of the objective function are represented by the utility function, which is defined over only the mean and standard deviation of the objective function. Multiple sources of risk can be accommodated easily within a quasi-linear objective function as a linear combination of multiple random variables, all of which are multivariate normally distributed within a location-scale family (Chamberlain, 1983; Owen \& Rabinovitch, 1983; Eichner \& Wagener, 2009; Alghalith, 2017; Huang \& Jiang, 2020; Padhi \& Mukherjee, 2021).

\section{The model}

Consider a single-output competitive generic drug firm's profit function under supply uncertainty brought about by input price risks as shown in Fig. 3.

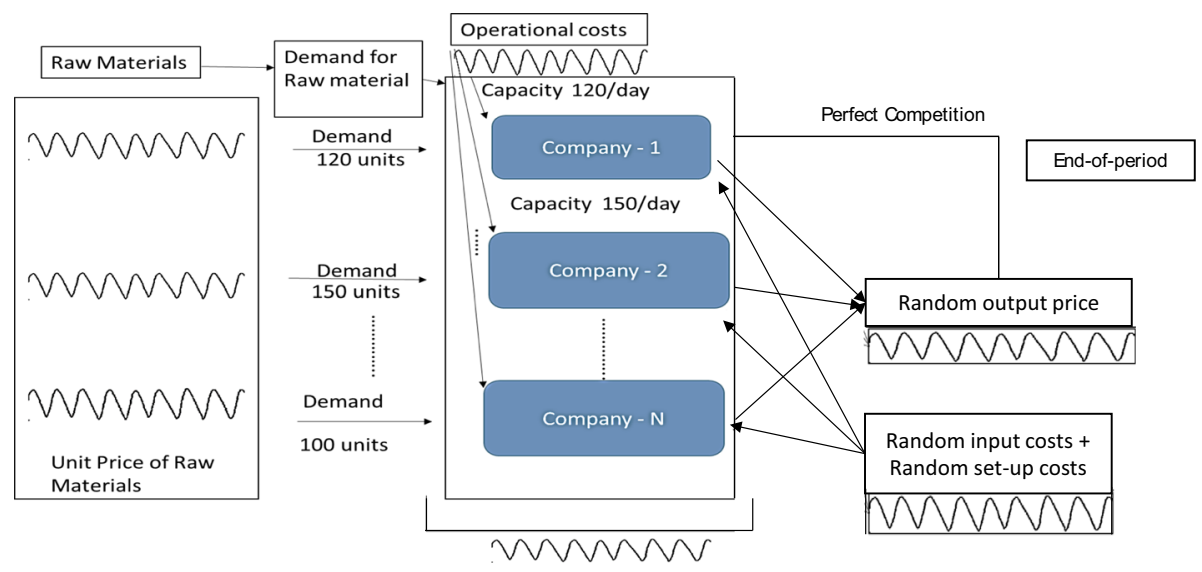

Fig. 3 Sourcing decision of a manufacturer under interconnected risks 
Therefore, we are considering only a partial equilibrium modelling approach, where the supply side (downstream) demand is deterministic. In this context, we consider a planning horizon with two periods i.e., $t=0$ (Initial period) and $t=1$ (Final period). To begin with, we assume $t=0$, the manufacturer decides to produce and sell a single product based on its known unit price, while the realizations of all the random input prices and the background risk take place at $t=1$. Without any loss of generality, we consider the manufacturer as risk averse.

$p_{x}$ is the regulated product price of the finally manufactured drug, $X$. The distribution of $\widetilde{p}_{v}$ follows an objective cumulative distribution function over $\left[\underline{p_{v}}, \overline{p_{v}}\right]$, denoting random per-unit price of input $v$ to produce output $x$. The production function $X=F(v)=A v$, with $A>0$. We assume that the operational cost of production is

$$
\widetilde{C(v)}=\widetilde{p_{v}} v+\tilde{Z}
$$

There is a random component of the operational cost to procure the input, denoted by $\tilde{Z}$. which is also a random variable over $[\underline{Z}, \bar{Z}] . \tilde{Z}$ can be categorized as the background risk that influences the manufacturer's input choice decision over which the manufacturer has no control, by affecting the total operational cost of input usage. As an example of such risk affecting the (operational) cost of production, one may look at Mukherjee et al. (2021). ${ }^{2}$ In the present context, this follows from the sourcing decision approach to interconnected risks in a SC system.

Hence, the profit function of the manufacturer is denoted as:

$$
\tilde{\pi}=p_{x} F(v)-\widetilde{C(v)}=p_{x} A v-\left(\tilde{p_{v}} v+\tilde{Z}\right)
$$

However, the following three standard assumptions to make the modelling approach comparable with the EU models and required analytical simplicity. Firstly, all feasible distributions of any random variable (either input price or the background risk) differ only with respect to the location (mean) and the scale (standard deviation) parameters. The locationscale condition in our context implies the set of possible profits that can be obtained by the decision maker's input choices contains only random variables $\left(\tilde{p_{v}}, \tilde{Z}\right)$, whose distributions vary from one another by location and scale parameters (i.e., by means and standard deviations). Secondly, both sources of uncertainty must interact linearly with the decision variable (see Meyer, 1987 for the validity of this assumption). In particular, both price risk and the background risk, are multivariate normally distributed for the location-scale condition (which is engrained in the literature, for example, Chamberlain, 1983; Eichner, 2008; Eichner \& Wagener, 2003, 2009, 2012; Owen \& Rabinovitch, 1983). Furthermore, given that the final profit is linear in both random variables, correlation (or covariance) serves as the most fitting parameter to characterize the interconnectedness between the two different sources of supply risks. In this context, the readers may see Embrechts et al. (2002); and Eichner and Wagener (2012).

$\mu$ represents the expected profit, where $\mu=E(\tilde{\pi})=p_{x} A v-\left(\mu_{v} v+\mu_{Z}\right)$.

$\sigma$ represents the profit-risk, where $\sigma=\sqrt{\sigma_{v}^{2} v^{2}+\sigma_{Z}^{2}+2 v \operatorname{cov}\left(\tilde{p_{v}}, \tilde{Z}\right)}$.

\footnotetext{
2 According to Mukherjee et al. (2021), variations in firm size, age and uncertain changes in the industryspecific policies over time (due to changes in management regimes) are going to affect the fixed operational cost of production (in the context of Mukherjee et al., 2021, for exportable) at the firm-level, over which the firm has no control.
} 
Here $\sigma_{v}, \sigma_{Z}$ and $\operatorname{cov}\left(\tilde{p_{v}}, \tilde{Z}\right)$ are respectively the standard deviation of input price risk, the standard deviation of background risk, and the correlation (i.e., connectivity of risks in a SC system) between both sources of risk. Without any loss of generality, we are assuming that $\left(\tilde{p_{v}}, \tilde{Z}\right)$ are multivariate normally distributed with means $\left(\mu_{v}, \mu_{Z}\right)$, variance-covariance structure $\left(\sigma_{v}, \sigma_{Z}, \operatorname{cov}\left(\tilde{p}_{v}, \tilde{Z}\right)\right)$.

For two symmetrically normally distributed random variables $\left(\tilde{p_{v}}, \tilde{Z}\right)$, with $\operatorname{cov}\left(\tilde{p_{v}}, \tilde{Z}\right)=\rho \sigma_{v} \sigma_{Z}$, the Pearson coefficient of correlation $\rho$ is a copula-based measure of concordance (or association) between these two normally distributed random variables (see, e.g., Embrechts et al., 2002; Eichner \& Wagener, 2009). Therefore, increasing the $\operatorname{cov}\left(\tilde{p_{v}}, \tilde{Z}\right)$, keeping $\sigma_{v}$ and $\sigma_{Z}$ constant implies that the two random variables are becoming more concordant.

Since variability in ex-post profits depend upon the distributions of $\tilde{p_{v}}$ and $\tilde{Z}$, changes in the covariances between random input price and the background risk, keeping the individual standard deviations constant, will definitely affect the optimal choice by altering the slopes of both the "indifference curve" (i.e., locus of equal utility, where the utility function is defined over the mean and standard deviation of the ex-post profit) and that of the opportunity frontier in the risk-return plane.

We are making the following assumption regarding the manufacturer's preference function defined over risk and return, where the preference function means the manufacturer's utility function that maps the manufacturer's choice over profit-risk $(\sigma)$ versus return $(\mu)$ in $\mathbb{R}_{+}$. Here our preference function is $U(\sigma, \mu)$, which follows the assumptions (1)-(4) mentioned below.

(1) For any random $\tilde{W}$ (where $\tilde{W} \in\left\{\tilde{\pi}, \tilde{p_{v}}, \tilde{Z}\right\}$ ), the utility function $U(\sigma, \mu)$ is, at least four times continuously differentiable.

(2) We have, the marginal utility with respect to (w.r.t. hereafter) $\mu_{W}$ as positive while the marginal utility w.r.t. $\sigma_{W}$ as negative i.e., $\partial U(\sigma, \mu) / \partial \mu>0, \partial U(\sigma, \mu) / \partial \sigma<0$. In other words, we are assuming that the manufacturer's preferences towards risk satisfy non-satiation (increasing in $\mu$ ) and the manufacturer is risk averse (decreasing in $\sigma$ ). ${ }^{3}$

(3) $U(\sigma, \mu)$ is strictly quasi-concave in $(\sigma, \mu)$. Hence,

$$
\begin{gathered}
{\left[-(\partial U(\sigma, \mu) / \partial \sigma)^{2}\left(\partial^{2} U(\sigma, \mu) / \partial \mu^{2}\right)-(\partial U(\sigma, \mu) / \partial \mu)^{2}\left(\partial^{2} U(\sigma, \mu) / \partial \sigma^{2}\right)\right.} \\
\left.+2(\partial U(\sigma, \mu) / \partial \mu)(\partial U(\sigma, \mu) / \partial \sigma)\left(\partial^{2} U(\sigma, \mu) / \partial \mu \partial \sigma\right)\right]>0
\end{gathered}
$$

The corresponding indifference curves (ICs hereafter) in $(\sigma, \mu)$-plane are positively sloped and strictly convex. Hence, $\left(\partial^{2} U(\sigma, \mu) / \partial \sigma^{2}\right)<0,\left(\partial^{2} U(\sigma, \mu) / \partial \mu^{2}\right)<0$. Therefore, from the above inequality for the quasi-concavity of the preference function, given assumption (2), we obtain $\left(\partial^{2} U(\sigma, \mu) / \partial \mu \partial \sigma\right)>0$.

(4) The ICs enter the $\mu$-axis with zero slope i.e., exhibiting risk-neutrality for very small risks.

The above-mentioned assumptions restrict this study to a risk averse manufacturer only, with monotonic and strictly quasi-concave preferences. Therefore, the manufacturer is worse off receiving an additional background risk $\tilde{Z}$, starting from an already uncertain end-ofperiod profit with random input prices. In other words, the compensation that is required for

\footnotetext{
3 While the usefulness and validity of marginal utilities to describe the risk preference pattern in an EU framework has been discussed in Meyer (2010); for the equivalence of the same in two-moment models, one can look at Eichner and Wagener (2003, 2005, 2009).
} 
facing background risk, in addition to the risk originating from the uncertain input prices, is higher than the compensation required for facing the risk owing to the uncertain input prices only.

Literature defines the marginal rate of substitution (MRS) between risk and return as the slope of the indifference curve in a two-dimensional plane i.e., in a $\sigma-\mu$ plane:

$$
S(\sigma(v), \mu(v))=-\frac{\partial U(\sigma(v), \mu(v)) / \partial \sigma(v)}{\partial U(\sigma(v), \mu(v)) / \partial \mu(v)} .
$$

$S()>$.0 is the two-parameter equivalent to Arrow-Pratt measure of absolute risk aversion (or equivalently, risk attitude). This represents the decision-maker's willingness to pay for a reduction in risk.

Before proceeding to the comparative static exercises, we are defining a few concepts below.

Definition 1 The elasticity of the MRS between risk and return with respect to the standard deviation of the manufacturer's random final profit is.

$$
\varepsilon_{\sigma}(v) \equiv \varepsilon_{\sigma}(\sigma(v), \mu(v))=\frac{\partial S(\sigma(v), \mu(v))}{\partial \sigma(v)} \frac{\sigma(v)}{S(\sigma(v), \mu(v))}, \text { with } \sigma(v)>0 .
$$

The elasticity $\varepsilon_{\sigma}(v)$ represents the proportional change in MRS over the proportional change in standard deviation of final profit, keeping the expected profit constant.

Definition 2 We define the elasticity of the MRS between risk and return with respect to the expected ex-post profit,

$$
\varepsilon_{\mu}(v)=\varepsilon_{\mu}(\sigma(v), \mu(v))=\frac{\partial S(\sigma(v), \mu(v))}{\partial \mu(v)} \frac{\mu(v)}{S(\sigma(v), \mu(v))} .
$$

i.e., elasticity $\varepsilon_{\mu}(v)$ represents the proportion change in MRS over the proportion change in expected final profit, keeping the standard deviation of the ex-post profit constant.

With these definitions in hand, let us begin with the first set of comparative static exercises, i.e., the decision of optimal input usage only concerning the alteration in the distribution of the input prices.

The major comparative static exercise we explore is how much the manufacturer optimally uses input (and, consequently, how much can he optimally manufacture) while facing uncertainties regarding the dependence structure or connectivity among different multivariate normally distributed risks.

The risk averse manufacturer solves the below mentioned problem,

$$
\max _{(v \geq 0)} U(\sigma(v), \mu(v)) .
$$

Subject to,

$$
\begin{gathered}
\mu(v)=p_{x} A v-\left(\mu_{v} v+\mu_{Z}\right) \\
\sigma(v)=\sqrt{\sigma_{v}^{2} v^{2}+\sigma_{Z}^{2}+2 v \operatorname{cov}\left(\tilde{p_{v}}, \tilde{Z}\right)}
\end{gathered}
$$

When we consider "interior solutions" to this decision problem (corner solution would fetch the possibility of $v^{*}=0$, which is not the focus of this study: since the manufacturer 
is risk averse), we determine the first-order condition (F.O.C.) for optimum solution as:

$$
A p_{x}-\mu_{v}-\left(\frac{\partial \sigma\left(v^{*}\right)}{\partial v}\right) S\left(\sigma\left(v^{*}\right), \mu\left(v^{*}\right)\right)=0
$$

Now, we have $\left(\frac{\partial \sigma\left(v^{*}\right)}{\partial v}\right)=\left[\sigma_{v}^{2} v^{*}+\operatorname{cov}\left(\widetilde{p_{v}}, \tilde{Z}\right)\right] \frac{1}{\sigma\left(v^{*}\right)}=\left[A p_{x}-\mu_{v}\right] / S\left(\sigma^{*}, \mu^{*}\right)>0$, since for a risk averse decision-maker, the expected risk premium (i.e. $A p_{x}-\mu_{v}$ ) must be positive, implying that $v^{*}>0$ : we are dealing with the "interior solution" of the F.O.C. in (3). Asterisk represents the optimum. Hence, $S\left(\sigma^{*}, \mu^{*}\right) \equiv S\left(\sigma\left(v^{*}\right), \mu\left(v^{*}\right)\right) \equiv S\left(v^{*}\right)>0$ at the optimum. Also, this implies $\operatorname{cov}\left(\tilde{p_{v}}, \tilde{Z}\right)>-\sigma_{v}^{2} v^{*}$.

The comparative static responses depend on the relative willingness-to-pay for a reduction in risk towards the changes in the expectation and variability of the final profit. The left-hand side (L.H.S) of the F.O.C. as described in Eq. 3 represents the slope of the "opportunity frontier" whereas the right-hand side (R.H.S) depicts the slope of the indifference curve.

Point $\mathrm{O}$ in Fig. 2 corresponds to the F.O.C. in (3): depicting the optimal $v$.

With this backdrop, let us trace out the influence on the decision of optimum input choice $\left(v^{*}\right)$ owing to the change in the dependence structure (in relative terms) between random input prices $\left(\widetilde{p_{v}}\right)$ and the random fixed set-up cost (i.e., the background risk component, $\tilde{Z}$ ). This comparative static exercise addresses the following research question: under what condition, a risk averse manufacturer optimally chooses lower $v$ when the two risks (background risk and input price risks) become more concordant, (i.e., owing to a small increase in $\operatorname{cov}\left(\tilde{p_{v}}, \tilde{Z}\right)$, given the individual standard deviations of the two risks)?

Focusing on the changes in the covariance of background risk, implicit differentiation of (3) w.r.t. $\operatorname{cov}\left(\tilde{p_{v}}, \tilde{Z}\right)$ yields

$$
\begin{aligned}
\operatorname{sgn}\left(\partial v^{*} / \partial \operatorname{cov}\left(\tilde{p_{v}}, \tilde{Z}\right)\right)= & -\operatorname{sgn}\left[\left(\partial^{2} \sigma\left(v^{*}\right) / \partial v \partial \operatorname{cov}\left(\tilde{p_{v}}, \tilde{Z}\right)\right) S\left(v^{*}\right)\right. \\
& \left.+\left(\frac{\partial \sigma\left(v^{*}\right)}{\partial v}\right)\left(\partial \sigma\left(v^{*}\right) / \partial \operatorname{cov}\left(\tilde{p_{v}}, \tilde{Z}\right)\right)\left\{\partial S\left(v^{*}\right) / \partial \sigma\left(v^{*}\right)\right\}\right]
\end{aligned}
$$

where

$$
\begin{gathered}
\sigma\left(v^{*}\right)\left(\partial^{2} \sigma\left(v^{*}\right) / \partial v \partial \operatorname{cov}\left(\tilde{p_{v}}, \tilde{Z}\right)\right)+\left(\partial \sigma\left(v^{*}\right) / \partial \operatorname{cov}\left(\tilde{p_{v}}, \tilde{Z}\right)\right)\left(\frac{\partial \sigma\left(v^{*}\right)}{\partial v}\right)=-A \\
\left(\partial \sigma\left(v^{*}\right) / \partial \operatorname{cov}\left(\tilde{p_{v}}, \tilde{Z}\right)\right)=-\left[A v^{*} / \sigma\left(v^{*}\right)\right] \\
\left(\partial^{2} \sigma\left(v^{*}\right) / \partial v \partial \operatorname{cov}\left(\tilde{p_{v}}, \tilde{Z}\right)\right)=\left[A v^{*} / \sigma^{2}\left(v^{*}\right)\right]\left(\frac{\partial \sigma\left(v^{*}\right)}{\partial v}\right)-A / \sigma\left(v^{*}\right) \\
=A / \sigma\left(v^{*}\right)\left[\left\{v^{*}\left(\partial \sigma\left(v^{*}\right) / \partial v\right)\right\} / \sigma\left(v^{*}\right)-1\right]
\end{gathered}
$$

Now we are going to demonstrate below that $\left\{v^{*}\left(\partial \sigma\left(v^{*}\right) / \partial v\right)\right\} / \sigma\left(v^{*}\right) \in(0,1)$.

$$
\begin{array}{r}
\left\{v^{*}\left(\partial \sigma\left(v^{*}\right) / \partial v\right)\right\} / \sigma\left(v^{*}\right)=\left[\sigma_{v}^{2} v^{* 2}+v^{*} \operatorname{cov}\left(\tilde{p_{v}}, \tilde{Z}\right)\right] \frac{1}{\sigma^{2}\left(v^{*}\right)} \\
=\frac{\sigma_{v}^{2} v^{* 2}+v^{*} \operatorname{cov}\left(\tilde{p_{v}}, \tilde{Z}\right)}{\sigma_{v}^{2} v^{* 2}+\sigma_{Z}^{2}+2 v^{*} \operatorname{cov}\left(\tilde{p_{v}}, \tilde{Z}\right)}
\end{array}
$$




$$
\begin{aligned}
& =\left[1-\left(\frac{\sigma_{Z}^{2}+v^{*} \operatorname{cov}\left(\tilde{p_{v}}, \tilde{Z}\right)}{\sigma_{v}^{2} v^{* 2}+\sigma_{Z}^{2}+2 v^{*} \operatorname{cov}\left(\tilde{p_{v}}, \tilde{Z}\right)}\right)\right] \\
& \in(0,1)
\end{aligned}
$$

Hence, $G\left(v^{*}\right)=\left\{v^{*}\left(\partial \sigma\left(v^{*}\right) / \partial v\right)\right\} / \sigma\left(v^{*}\right) \in(0,1)$.

Therefore, equivalently,

$$
G\left(v^{*}\right) /\left\{1+G\left(v^{*}\right)\right\}=\left[1 /\left\{1+\frac{1}{G\left(v^{*}\right)}\right\}\right]<0.5
$$

From (4), after substituting values from (5.1)-(6) and then with some manipulations it can be verified that.

$$
\begin{aligned}
& \partial v^{*} / \partial \operatorname{cov}\left(\widetilde{p_{v}}, \tilde{Z}\right)<0, \text { iff } \\
& \qquad\left(\frac{\partial \sigma\left(v^{*}\right)}{\partial v}\right)\left(\partial \sigma\left(v^{*}\right) / \partial \operatorname{cov}\left(\widetilde{p_{v}}, \tilde{Z}\right)\right)\left\{\partial S\left(v^{*}\right) / \partial \sigma\left(v^{*}\right)\right\}>-\left(\partial^{2} \sigma\left(v^{*}\right) / \partial v \partial \operatorname{cov}\left(\widetilde{p_{v}}, \tilde{Z}\right)\right) S\left(v^{*}\right)
\end{aligned}
$$

Using (5.1), we obtain, $\partial v^{*} / \partial \operatorname{cov}\left(\tilde{p_{v}}, \tilde{Z}\right)<0$, iff

$$
\begin{aligned}
& \left(\frac{\partial \sigma\left(v^{*}\right)}{\partial v}\right)\left(\partial \sigma\left(v^{*}\right) / \partial \operatorname{cov}\left(\tilde{p_{v}}, \tilde{Z}\right)\right)\left\{\partial S\left(v^{*}\right) / \partial \sigma\left(v^{*}\right)\right\} \\
& +\left(\partial \sigma\left(v^{*}\right) / \partial \operatorname{cov}\left(\tilde{p_{v}}, \tilde{Z}\right)\right)\left(\frac{\partial \sigma\left(v^{*}\right)}{\partial v}\right) \frac{1}{\sigma\left(v^{*}\right)}>-A / \sigma\left(v^{*}\right)
\end{aligned}
$$

Substituting back from (5.2) into above inequality, we obtain,

$$
-A\left[\left\{v^{*}\left(\partial \sigma\left(v^{*}\right) / \partial v\right)\right\} / \sigma\left(v^{*}\right)\right]\left[\left\{\partial S\left(v^{*}\right) / \partial \sigma\left(v^{*}\right)\right\} \sigma\left(v^{*}\right)+1\right]>-A
$$

or,

$$
G\left(v^{*}\right)\left[\left\{\partial S\left(v^{*}\right) / \partial \sigma\left(v^{*}\right)\right\} \sigma\left(v^{*}\right)+1\right]>1
$$

or,

$$
\left[\left\{\partial S\left(v^{*}\right) / \partial \sigma\left(v^{*}\right)\right\} \sigma\left(v^{*}\right)+1\right]>\left(1 / G\left(v^{*}\right)\right)>1
$$

or,

$$
\left\{\partial S\left(v^{*}\right) / \partial \sigma\left(v^{*}\right)\right\} \sigma\left(v^{*}\right)>0
$$

Hence, (7.1) is equivalent to stating that

$$
\left\{\partial^{2} S\left(v^{*}\right) / \partial \sigma\left(v^{*}\right)^{2}\right\} \sigma\left(v^{*}\right)+\left\{\partial S\left(v^{*}\right) / \partial \sigma\left(v^{*}\right)\right\}>0
$$

Eichner and Wagener (2003, 2009); Eichner () show that convexity of the slope of $(\sigma, \mu)$-indifference curves with respect to $\sigma($.$) , i.e., \left\{\partial^{2} S(.) / \partial \sigma(.)^{2}\right\}>0$, together with $\{\partial S(.) / \partial \sigma()\}>$.0 demonstrate the "variance vulnerable" behaviour of the manufacturer, when $\mathrm{s} / \mathrm{he}$ experiences greater interconnectedness between the input price risk and the background risk. It can be easily verified from (7.1) and Definition 1 that $\partial v^{*} / \partial \operatorname{cov}\left(\tilde{p_{v}}, \tilde{Z}\right)<0$ iff $\left\{\partial S\left(v^{*}\right) / \partial \sigma\left(v^{*}\right)\right\}>0$ (i.e., "variance vulnerability"), or, equivalently, $\boldsymbol{\varepsilon}_{\boldsymbol{\sigma}}\left(\boldsymbol{v}^{*}\right)>0$.

This result shows that the risk averse manufacturer might be inclined to supply less when there is a high concurrence between the input price risk and the background risk (i.e., the input price risk and the background risk are tightly coupled), contrary to the scenario when the 
correlation between the two sources of risk is low (i.e., when both risks are loosely coupled). However, this will happen if and only if (often abbreviated in the paper as 'iff') $\varepsilon_{\sigma}\left(v^{*}\right)>0$. We summarize the findings in the following proposition.

Proposition 1 . If the input price risk and the background risk are become tightly (loosely) coupled, the manufacturer might behave in more (less) risk averse fashion, if and only if $\varepsilon_{\sigma}()>$.0 .

\section{Analysis with output price risk}

Let's now assume that the manufacturer is now facing a random price-shock in the output (product) market as well. With output price risk, the inter-connected background risk will make the manufacturer more vulnerable towards price risk and thereby influence the manufacturer's optimal risk-taking. This is because

$$
\begin{gathered}
\mu=\mu_{p} A v-\left(\mu_{v} v+\mu_{Z}\right) \\
\sigma=\left[\sigma_{p}^{2} A^{2} v^{2}+\left(\sigma_{v}^{2} v^{2}+\sigma_{Z}^{2}+2 v \operatorname{cov}\left(\widetilde{p_{v}}, \tilde{Z}\right)\right)-2 A v\left[v \operatorname{cov}\left(\widetilde{p_{v}}, \widetilde{p_{x}}\right)+\operatorname{cov}\left(\widetilde{p_{x}}, \tilde{Z}\right)\right]\right]^{\frac{1}{2}} \\
A \mu_{p}-\mu_{v}-\left(\frac{\partial \sigma\left(v^{*}\right)}{\partial v}\right) S\left(\sigma^{*}, \mu^{*}\right)=0 \\
\left(\frac{\partial \sigma\left(v^{*}\right)}{\partial v}\right)=\frac{1}{\sigma}\left[\sigma_{p}^{2} A^{2} v^{*}+\left\{\sigma_{v}^{2} v^{*}+\operatorname{cov}\left(\widetilde{p_{v}}, \tilde{Z}\right)\right\}-A v^{*} \operatorname{cov}\left(\widetilde{p_{v}}, \widetilde{p_{x}}\right)\right. \\
\left.-A\left[v^{*} \operatorname{cov}\left(\widetilde{p_{v}}, \widetilde{p_{x}}\right)+\operatorname{cov}\left(\widetilde{p_{x}}, \tilde{Z}\right)\right]\right]
\end{gathered}
$$

For a risk averse manufacturer with $S\left(\sigma^{*}, \mu^{*}\right)>0$ and positive risk premium, we have, $\left(\mu_{p} / \mu_{v}\right)>1 / A$. Hence, $\left(\frac{\partial \sigma\left(v^{*}\right)}{\partial v}\right)>0$. Along with this, the quasi-concavity of $U(\sigma, \mu)$ and multivariate normal distribution between the risks ensure that we have the second-order condition for maximum is satisfied with interior solution for $v^{*}$.

Multiple sources of risk enter our objective function (here ex-post profit of the manufacturer) as a linear combination of multiple random variables, wherein we assume that all of them are multivariate normally distributed for the location-scale condition (which is engrained in the literature, for example, Chamberlain, 1983; Eichner, 2008; Eichner \& Wagener, 2003, 2009, 2012; Owen \& Rabinovitch, 1983). Without any loss of generality, we are assuming that the vector comprising the random variables $\left(\widetilde{p_{x}}, \tilde{p_{v}}, \tilde{Z}\right)$ would be multivariate normally distributed with means $\left(\mu_{x}, \mu_{v}, \mu_{Z}\right)$ and the variance-covariance structure $\left(\sigma_{x}, \sigma_{v}, \sigma_{Z}, \operatorname{cov}\left(\widetilde{p_{x}}, \widetilde{p_{v}}\right), \operatorname{cov}\left(\widetilde{p_{v}}, \tilde{Z}\right), \operatorname{cov}\left(\widetilde{p_{x}}, \tilde{Z}\right)\right)$. Hence, covariances between the pairs of these random variables fully encapsulate the dependence structure between them. We further assume that for two symmetrically normally distributed random variables $\left(\widetilde{p_{x}}, \tilde{Z}\right)$, with $\operatorname{cov}\left(\widetilde{p_{x}}, \tilde{Z}\right)=\rho_{x} \sigma_{x} \sigma_{Z}$ (and similarly for the other two pairs), the Pearson coefficient of correlation $\rho_{x Z}$ is a copula-based measure of concordance (or association) between these two normally distributed random variables (see, e.g., Embrechts et al., 2002; Eichner $\&$ Wagener, 2009). Therefore, increasing the $\operatorname{cov}\left(\widetilde{p_{x}}, \tilde{Z}\right)$, keeping $\sigma_{x}$ and $\sigma_{Z}$ and other parameters constant implies that these two random variables are becoming more concordant. Since variability in ex-post profits depend upon the distributions of $\widetilde{p_{x}}$ and $\tilde{Z}$, changes in the covariances between random product price and the background risk, keeping the individual 
standard deviations constant, will definitely affect the optimal choice by altering the slopes of both the indifference curve and that of the opportunity frontier in the risk-return plane.

In this case, we work out for an increase in $\operatorname{cov}\left(\widetilde{p_{x}}, \tilde{Z}\right)$ and in $\operatorname{cov}\left(\widetilde{p_{x}}, \widetilde{p_{v}}\right)$ on the optimum $v^{*}$.

(a) Increase in $\operatorname{cov}\left(\widetilde{\boldsymbol{p}_{\boldsymbol{x}}}, \tilde{\boldsymbol{Z}}\right)$

The following comparative static exercise guides us on how an increase in the covariance (correlation) between the output price risk and background risk, keeping the variances of these two risks and other parameters unchanged, would affect the optimal risk-taking of the manufacturer.

$$
\begin{aligned}
\operatorname{sgn}\left(\partial v^{*} / \partial \operatorname{cov}\left(\widetilde{p_{x}}, \tilde{Z}\right)\right)= & -\operatorname{sgn}\left[\left(\partial^{2} \sigma\left(v^{*}\right) / \partial v \partial \operatorname{cov}\left(\widetilde{p_{x}}, \tilde{Z}\right)\right) S\left(v^{*}\right)\right. \\
& \left.+\left(\frac{\partial \sigma\left(v^{*}\right)}{\partial v}\right)\left(\partial \sigma\left(v^{*}\right) / \partial \operatorname{cov}\left(\widetilde{p_{x}}, \tilde{Z}\right)\right)\left\{\partial S\left(v^{*}\right) / \partial \sigma\left(v^{*}\right)\right\}\right]
\end{aligned}
$$

where from (9), we obtain

$$
\sigma\left(v^{*}\right)\left(\partial^{2} \sigma\left(v^{*}\right) / \partial v \partial \operatorname{cov}\left(\widetilde{p_{x}}, \tilde{Z}\right)\right)+\left(\partial \sigma\left(v^{*}\right) / \partial \operatorname{cov}\left(\widetilde{p_{x}}, \tilde{Z}\right)\right)\left(\frac{\partial \sigma\left(v^{*}\right)}{\partial v}\right)=-A \text {; }
$$

Or,

$$
\left(\partial^{2} \sigma\left(v^{*}\right) / \partial v \partial \operatorname{cov}\left(\widetilde{p_{x}}, \tilde{Z}\right)\right)=-\left[\frac{A+\left(\partial \sigma\left(v^{*}\right) / \partial \operatorname{cov}\left(\widetilde{p_{x}}, \tilde{Z}\right)\right)\left(\frac{\partial \sigma\left(v^{*}\right)}{\partial v}\right)}{\sigma\left(v^{*}\right)}\right]
$$

And,

$$
\left(\partial \sigma\left(v^{*}\right) / \partial \operatorname{cov}\left(\widetilde{p_{x}}, \tilde{Z}\right)\right)=-\left[A v^{*} / \sigma\left(v^{*}\right)\right]
$$

Therefore, substituting values from (11)-(13) back into (10), and after some simplifications, we obtain,

$$
\begin{gathered}
\operatorname{sgn}\left(\partial v^{*} / \partial \operatorname{cov}\left(\widetilde{p_{x}}, \tilde{Z}\right)\right)=\operatorname{sgn}\left[S\left(v^{*}\right)\left(\left\{A+\left(\partial \sigma\left(v^{*}\right) / \partial \operatorname{cov}\left(\widetilde{p_{x}}, \tilde{Z}\right)\right)\left(\frac{\partial \sigma\left(v^{*}\right)}{\partial v}\right)\right\} / \sigma\left(v^{*}\right)\right)\right. \\
\left.+\left(\frac{\partial \sigma\left(v^{*}\right)}{\partial v}\right)\left(\partial \sigma\left(v^{*}\right) / \partial \operatorname{cov}\left(\widetilde{p_{x}}, \tilde{Z}\right)\right)\left\{\partial S\left(v^{*}\right) / \partial \sigma\left(v^{*}\right)\right\}\right] \\
=\operatorname{sgn}\left[A+\left(\partial \sigma\left(v^{*}\right) / \partial \operatorname{cov}\left(\widetilde{p_{x}}, \tilde{Z}\right)\right)\left(\partial \sigma\left(v^{*}\right) / \partial v\right)\left\{1+\left(\partial S\left(v^{*}\right) / \partial \sigma\left(v^{*}\right)\right)\left(\sigma\left(v^{*}\right) / S\left(v^{*}\right)\right)\right\}\right] \\
=\operatorname{sgn}\left[A+\left(\partial \sigma\left(v^{*}\right) / \partial \operatorname{cov}\left(\widetilde{p_{x}}, \tilde{Z}\right)\right)\left(\partial \sigma\left(v^{*}\right) / \partial v\right)\left\{1+\varepsilon_{\sigma}\left(\sigma\left(v^{*}\right), \mu\left(v^{*}\right)\right)\right\}\right]
\end{gathered}
$$

From here, it is imminent that $\operatorname{sgn}\left(\partial v^{*} / \partial \operatorname{cov}\left(\widetilde{p_{x}}, \tilde{Z}\right)\right)>0$ if and only if $\operatorname{sgn}\left[\left(\partial \sigma\left(v^{*}\right) / \partial v\right)\left(\partial \sigma\left(v^{*}\right) / \partial \operatorname{cov}\left(\widetilde{p_{x}}, \tilde{Z}\right)\right)\left\{1+\varepsilon_{\sigma}\left(v^{*}\right)\right\}\right]>0$; or, equivalently, $\varepsilon_{\sigma}\left(v^{*}\right)>$ -1 holds.

Proposition 2 . If the output price risk and the background risk become tightly (loosely) coupled, the manufacturer might behave in less (more) risk averse fashion, if and only if $\varepsilon_{\sigma}()>$.-1 . 
An increase in interconnectivity of the output price risk and background risk, $\operatorname{cov}\left(\widetilde{p_{x}}, \tilde{Z}\right)$, has two effects: first, for any given input choice, it decreases the variability in overall profit. This will lead to a lessened slope of the indifference curve for 'variance vulnerable' preferences. Second, it declines the marginal contribution of input choice on the overall profit-risk. This increases the firm's relative willingness to pay, by altering the slope of the mean-standard deviation opportunity frontier.

Proposition 2 states that an increase the concordance between the output price risk and background risk (i.e., the output price risk becomes tightly coupled with the background risk), ceteris paribus, leads to a reduction in the profit-risk and increases $v^{*}$, if the slope of the indifference curve responds "more strongly" than the slope of the mean-standard deviation opportunity frontier, given by the necessary and sufficient condition that $\varepsilon_{\sigma}($.) $>-1$. This sufficiency condition ensures that the reduction in variability of ex-post profit will increase $v^{*}$ upon increase in $\operatorname{cov}\left(\widetilde{p_{x}}, \tilde{Z}\right)$.

Now we are going to explore how an increase in the interconnectivity (covariance) between the output price risk and the input price risk, keeping the variances of these two risks and other parameters unchanged, would affect the optimal risk-taking of the manufacturer.

(b) Increase in $\operatorname{cov}\left(\widetilde{p_{x}}, \widetilde{p_{v}}\right)$

$$
\begin{aligned}
& \operatorname{sgn}\left(\partial v^{*} / \partial \operatorname{cov}\left(\widetilde{p_{v}}, \widetilde{p_{x}}\right)\right)=-\operatorname{sgn}\left[\left(\partial^{2} \sigma\left(v^{*}\right) / \partial v \partial \operatorname{cov}\left(\widetilde{p_{v}}, \widetilde{p_{x}}\right)\right) S\left(v^{*}\right)\right. \\
&\left.+\left(\frac{\partial \sigma\left(v^{*}\right)}{\partial v}\right)\left(\partial \sigma\left(v^{*}\right) / \partial \operatorname{cov}\left(\widetilde{p_{v}}, \widetilde{p_{x}}\right)\right)\left\{\partial S\left(v^{*}\right) / \partial \sigma\left(v^{*}\right)\right\}\right] \\
& \sigma\left(v^{*}\right)\left(\partial^{2} \sigma\left(v^{*}\right) / \partial v \partial \operatorname{cov}\left(\widetilde{p_{v}}, \widetilde{p_{x}}\right)\right)+\left(\partial \sigma\left(v^{*}\right) / \partial \operatorname{cov}\left(\widetilde{p_{v}}, \widetilde{p_{x}}\right)\right)\left(\frac{\partial \sigma\left(v^{*}\right)}{\partial v}\right)=-2 A v^{*}
\end{aligned}
$$

Given (15), we can make the following manipulation:

$$
\begin{gathered}
\operatorname{sgn}\left(\partial v^{*} / \partial \operatorname{cov}\left(\widetilde{p_{v}}, \widetilde{p_{x}}\right)\right)=-\operatorname{sgn}\left[\left(\partial^{2} \sigma\left(v^{*}\right) / \partial v \partial \operatorname{cov}\left(\widetilde{p_{v}}, \widetilde{p_{x}}\right)\right) \sigma\left(v^{*}\right)\right. \\
\left.+\left(\frac{\partial \sigma\left(v^{*}\right)}{\partial v}\right)\left(\partial \sigma\left(v^{*}\right) / \partial \operatorname{cov}\left(\widetilde{p_{v}}, \widetilde{p_{x}}\right)\right)\left\{\partial S\left(v^{*}\right) / \partial \sigma\left(v^{*}\right)\right\} \frac{\sigma\left(v^{*}\right)}{S\left(v^{*}\right)}\right] \\
=\operatorname{sgn}\left[2 A v^{*}+\left(\partial \sigma\left(v^{*}\right) / \partial \operatorname{cov}\left(\widetilde{p_{v}}, \widetilde{p_{x}}\right)\right)\left(\frac{\partial \sigma\left(v^{*}\right)}{\partial v}\right)\right. \\
\left.-\left(\frac{\partial \sigma\left(v^{*}\right)}{\partial v}\right)\left(\partial \sigma\left(v^{*}\right) / \partial \operatorname{cov}\left(\widetilde{p_{v}}, \widetilde{p_{x}}\right)\right) \varepsilon_{\sigma}\left(v^{*}\right)\right] \\
=\operatorname{sgn}\left[2 A v^{*}+\left(\partial \sigma\left(v^{*}\right) / \partial \operatorname{cov}\left(\widetilde{p_{v}}, \widetilde{p_{x}}\right)\right)\left(\frac{\partial \sigma\left(v^{*}\right)}{\partial v}\right)\left\{1-\varepsilon_{\sigma}\left(v^{*}\right)\right\}\right]
\end{gathered}
$$

whereas,

$$
\left(\partial \sigma\left(v^{*}\right) / \partial \operatorname{cov}\left(\widetilde{p_{v}}, \widetilde{p_{x}}\right)\right)=-\left[A v^{* 2} / \sigma\left(v^{*}\right)\right]
$$

Therefore, substituting $\left(\partial \sigma\left(v^{*}\right) / \partial \operatorname{cov}\left(\widetilde{p_{v}}, \widetilde{p_{x}}\right)\right)$ back from (17) into (16), we obtain,

$$
\begin{aligned}
\operatorname{sgn}\left(\partial v^{*} / \partial \operatorname{cov}\left(\widetilde{p_{v}}, \widetilde{p_{x}}\right)\right)= & \operatorname{sgn}\left[2 A v^{*}-\left\{A v^{* 2} / \sigma\left(v^{*}\right)\right\}\left(\frac{\partial \sigma\left(v^{*}\right)}{\partial v}\right)\left\{1-\varepsilon_{\sigma}\left(v^{*}\right)\right\}\right] \\
& =A v^{*} \operatorname{sgn}\left[2-\left\{v^{*} / \sigma\left(v^{*}\right)\right\}\left(\partial \sigma\left(v^{*}\right) / \partial v\right)\left\{1-\varepsilon_{\sigma}\left(v^{*}\right)\right\}\right]
\end{aligned}
$$




$$
=A v^{*} \operatorname{sgn}\left[1+\left(1-\left\{G\left(v^{*}\right)+1\right\}\left\{1-\varepsilon_{\sigma}\left(v^{*}\right)\right\}\right)\right]
$$

Therefore, $\left(\partial v^{*} / \partial \operatorname{cov}\left(\widetilde{p_{v}}, \widetilde{p_{x}}\right)\right)>0$, iff $1-\left\{G\left(v^{*}\right)+1\right\}\left\{1-\varepsilon_{\sigma}\left(v^{*}\right)\right\}>0$, or, $\left\{1-\varepsilon_{\sigma}\left(v^{*}\right)\right\}<\left[1 /\left\{G\left(v^{*}\right)+1\right\}\right]<1$; or, equivalently, $\varepsilon_{\sigma}\left(v^{*}\right)>0$.

Proposition 3 . If the output price risk and the input price risk are going to become tightly (loosely) coupled, the manufacturer might behave in less (more) risk averse fashion, if and only if $\varepsilon_{\sigma}()>$.0 .

Proposition 3 illustrates the following scenario. If the output price risk becomes more concordant with the input price risk, keeping individual variances and other parameters of the moment distributions constant, leads to a reduction in the profit-risk and increases optimum risk-taking, if the slope of the indifference curve responds "more strongly" than the slope of the mean-standard deviation opportunity frontier, given by the necessary and sufficient condition that $\varepsilon_{\sigma}()>$.0 . This sufficiency condition ensures that the reduction in variability of ex-post profit will increase $v^{*}$ upon increase in $\operatorname{cov}\left(\widetilde{p_{v}}, \widetilde{p_{x}}\right)$. if and only if $\varepsilon_{\sigma}()>$.0 holds.

\section{A parametric example to carry out sensitivity analysis of risk-taking for perturbation in the dependence structure/interconnectivity of risks.}

We provide a parametric example to demonstrate quantitatively the validity of our primary results for a risk averse manufacturer's preference under mean-standard deviation approach. For analytical simplicity we consider zero-subsidy scenario only.

Since our focus is the inter-connectivity of risks, i.e., when keeping the variances fixed, only correlations vary and thus altering the dependence structure among these multivariate normally distributed risks, we take $A=2, \sigma_{p}^{2}=\sigma_{v}^{2}=\sigma_{Z}^{2}=\sigma_{c}^{2} ; \mu_{p}=\mu_{v}=\bar{\mu}_{c} ; \mu_{Z}=$ $0 ; \rho_{x v}=\operatorname{cov}\left(\widetilde{p_{x}}, \widetilde{p_{v}}\right) / \sigma_{c}^{2} ; \rho_{v Z}=\operatorname{cov}\left(\widetilde{p_{v}}, \tilde{Z}\right) / \sigma_{c}^{2} ; \rho_{x Z}=\operatorname{cov}\left(\widetilde{p_{x}}, \tilde{Z}\right) / \sigma_{c}^{2} ; \rho_{x v} \neq \rho_{x Z} \neq$ $\rho_{x Z} \neq 0$.

We employ the following flexible utility function, as pioneered in Saha (1997).

$$
U=\mu^{a}-\sigma^{b}
$$

Saha (1997) termed this utility function as "Mean-Standard Deviation Utility Function" (or 'MSU'). The reason for adopting this special form of utility function is precisely to bring in the equivalence of the risk preferences under expected utility set-up and the mean-standard deviation preferences. Under the chosen MSU, one can easily categorise different kinds of risk preferences (risk aversion, risk neutrality and risk affinity) and various degrees of absolute and relative risk aversions. Therefore, for exemplification purpose, our parametric representation of risk preferences works fine (see Eichner \& Wagener, 2009; Broll et al., 2015; Broll \& Mukherjee, 2017; Broll et al., 2019; Mukherjee et al., 2021; Padhi \& Mukherjee, 2021 for application of this MSU to exemplify the pattern of risk preferences in a nonlinear mean-standard deviations framework). The F.O.C. of the manufacturer's decision problem suggests slope of the opportunity frontier must be equal to the MRS as in Saha (1997, p. 773). Our optimization exercise becomes, $\max U(\mu, \sigma)$ with,

$\mu=\bar{\mu}_{c} v$, and $\sigma=\sigma_{c}\left[\left(5 v^{2}+1\right)+2 v\left\{\rho_{v Z}-2\left(v \rho_{v x}+\rho_{x Z}\right)\right\}\right]^{\frac{1}{2}}$.

The F.O.C. becomes:

$$
\frac{\bar{\mu}_{c}}{2 \sigma_{c}^{2}\left[5 v^{*}+\rho_{v Z}-4 v^{*} \rho_{v x}-2 \rho_{x Z}\right]}=(b / a) \mu^{1-a} \sigma^{b-1}
$$


Table 1 Optimum $\boldsymbol{v}$ for different $\rho_{\boldsymbol{v}} \boldsymbol{Z}$ 's at the benchmark values of other moment-parameters, with $\boldsymbol{a}=2$; $\bar{\mu}_{c}=3.5 ; \sigma_{c}=0.3 ; \boldsymbol{b}=3$

\begin{tabular}{llllllllll}
\hline$\rho_{v Z}$ & 0.2 & 0.3 & 0.4 & 0.5 & 0.6 & 0.7 & 0.8 & 0.9 & 1.0 \\
\hline$\rho_{x v}$ & 0.5 & 0.5 & 0.5 & 0.5 & 0.5 & 0.5 & 0.5 & 0.5 & 0.5 \\
$\rho_{x z}$ & 0.5 & 0.5 & 0.5 & 0.5 & 0.5 & 0.5 & 0.5 & 0.5 & 0.5 \\
$\boldsymbol{v}^{*}$ & 1.12 & 1.10 & .08 & 1.06 & 1.04 & 1.02 & 1.00 & 0.98 & 0.96 \\
\hline
\end{tabular}

Table 2 Optimum $\boldsymbol{v}$ for different $\rho_{v} \boldsymbol{Z}$ 's at the benchmark values of other moment-parameters, with $\boldsymbol{a}=3$; $\bar{\mu}_{c}=3.5 ; \sigma_{c}=0.3 ; \boldsymbol{b}=4$

\begin{tabular}{llllllllll}
\hline$\rho_{v Z}$ & 0.2 & 0.3 & 0.4 & 0.5 & 0.6 & 0.7 & 0.8 & 0.9 & 1.0 \\
\hline$\rho_{\boldsymbol{x} v}$ & 0.5 & 0.5 & 0.5 & 0.5 & 0.5 & 0.5 & 0.5 & 0.5 & 0.5 \\
$\rho_{\boldsymbol{x} z}$ & 0.5 & 0.5 & 0.5 & 0.5 & 0.5 & 0.5 & 0.5 & 0.5 & 0.5 \\
$\boldsymbol{v}^{*}$ & 1.12 & 1.11 & 1.10 & 1.09 & 1.08 & 1.07 & 1.06 & 1.05 & 1.04 \\
\hline
\end{tabular}

$$
a \mu^{a-1} \bar{\mu}_{c}-b \sigma_{c}^{2} \sigma^{*(b-2)}\left[5 v^{*}+\rho_{v Z}-2\left(2 v^{*} \rho_{v x}+\rho_{x Z}\right)\right]=0
$$

Alternatively,

$$
a \mu^{a-1} \bar{\mu}_{c}=b \sigma_{c}^{2} \sigma^{*(b-2)}\left[5 v^{*}+\rho_{v Z}-2\left(2 v^{*} \rho_{v x}+\rho_{x Z}\right)\right]
$$

According to the "Definition 1" and "Definition 2", the elasticities of risk aversion with respect to the standard deviation and mean of the random final profit are respectively,

$\varepsilon_{\sigma}=b-1, \varepsilon_{\mu}=1-a$.

Taking logarithms on both sides of (11) and after some simplifications, we obtain,

$$
\begin{aligned}
a \ln \bar{\mu}_{c}-\ln (b / a)+ & (a-1) \ln v^{*}-b \ln \sigma_{c}-0.5(b-2) \ln \left[5 v^{*}+\rho_{v Z}-2\left(2 v^{*} \rho_{v x}+\rho_{x Z}\right)\right] \\
- & \ln \left[5 v^{*}+\rho_{v Z}-2\left(2 v^{*} \rho_{v x}+\rho_{x Z}\right)\right]=0
\end{aligned}
$$

Let us present a numerical example to illustrate Propositions $1-3 .{ }^{4}$

Our objective is to find optimal $v$ (i.e., $v^{*}$ ) from (21) as functions of $\left(a, b, \bar{\mu}_{c}, \sigma_{c}, \rho_{v Z}, \rho_{x v}, \rho_{x Z}\right)$ under the set of standardised values in Tables 1, 2, 3 and 4, which is based on the time-series data of 52 months (Jan 2013 to May 2017) for an Indiabased generic multi-vitamin manufacturer operating under "Pradhan Mantri Bhartiya Jan Aushadhi Kendra".

Simulation results demonstrate the facts established in Proposition 1-3.

Figure 4A illustrates the fact that with greater interconnectedness between the two supplyside risks, viz., with higher covariance/correlation between the random input prices and random set-up costs, would induce the manufacturer to opt for lower quantity of inputs at the margin. This is precisely because keeping the standard deviations and other parameters unchanged, an increase in $\rho_{v Z}$ leads to a reduction in the expected ex-post profit, which reduces input choice under the sufficiency condition of DARA preference structure $(a>$

4 Unfortunately, the BPPI (Bureau of Pharma Public Sector Undertakings of India) does not permit the researchers to disclose detailed data source. 
Table 3 Optimum $\boldsymbol{v}$ for different $\rho_{x \boldsymbol{v}}$ 's at the benchmark values of other moment-parameters, with $\boldsymbol{a}=2$; $\bar{\mu}_{c}=3.5 ; \sigma_{c}=0.3 ; b=3$

\begin{tabular}{lllllllllll}
\hline$\rho_{v Z}$ & 0.5 & 0.5 & 0.5 & 0.5 & 0.5 & 0.5 & 0.5 & 0.5 & 0.5 & 0.5 \\
\hline$\rho_{x v}$ & 0.1 & 0.2 & 0.3 & 0.4 & 0.5 & 0.6 & 0.7 & 0.8 & 0.9 & 1.0 \\
$\rho_{x z}$ & 0.5 & 0.5 & 0.5 & 0.5 & 0.5 & 0.5 & 0.5 & 0.5 & 0.5 & 0.5 \\
$\boldsymbol{v}^{*}$ & 2.1 & 2.3 & 2.4 & 2.5 & 2.7 & 2.9 & 3.1 & 3.4 & 3.7 & 4.1 \\
\hline
\end{tabular}

Table 4 Optimum $v$ for different $\rho_{x}$ 's at the benchmark values of other moment-parameters, with $\boldsymbol{a}=2$; $\bar{\mu}_{c}=3.5 ; \sigma_{c}=0.3 ; b=3$

\begin{tabular}{lllllllllll}
\hline$\rho_{v Z}$ & 0.5 & 0.5 & 0.5 & 0.5 & 0.5 & 0.5 & 0.5 & 0.5 & 0.5 & 0.5 \\
\hline$\rho_{x v}$ & 0.5 & 0.5 & 0.5 & 0.5 & 0.5 & 0.5 & 0.5 & 0.5 & 0.5 & 0.5 \\
$\rho_{x z}$ & 0.1 & 0.2 & 0.3 & 0.4 & 0.5 & 0.6 & 0.7 & 0.8 & 0.9 & 1.0 \\
$\boldsymbol{v}^{*}$ & 2.7 & 2.8 & 2.9 & 3.0 & 3.2 & 3.4 & 3.6 & 4.0 & 4.3 & 4.7 \\
\hline
\end{tabular}

$\mathbf{A}_{1.15}$

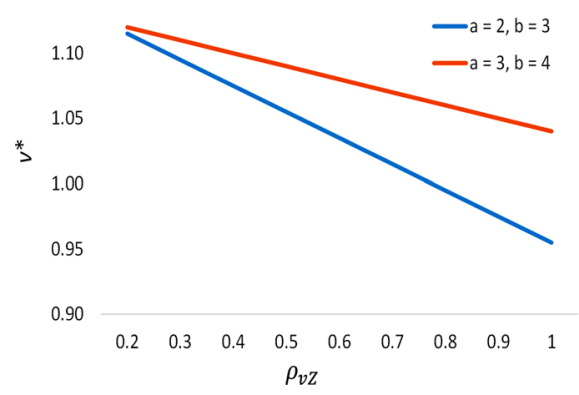

$\mathbf{B}_{5.0}$

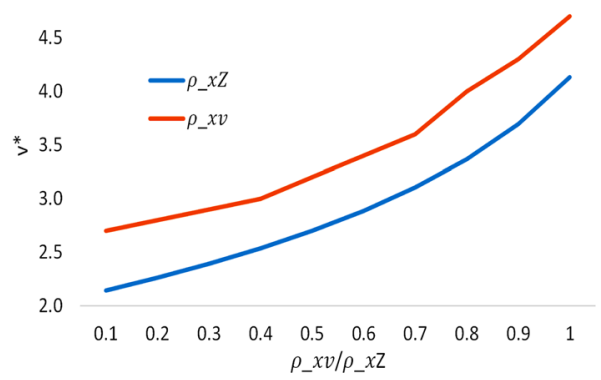

Fig. 4 Sensitivity Analysis to demonstrate Propositions

1). However, increase in $\rho_{v Z}$ also reduces the variability in the ex-post profit. 'Variance vulnerable' preference $(b>2)$ ensures that the slope of $(\sigma, \mu)$ indifference curve will decrease, and that the reduction in the slope of indifference curve responds more strongly than the slope of the 'opportunity frontier'. This prompts the risk averse manufacturer to opt for lower inputs at the optimum.

Figure 4B illustrates exactly the opposite outcomes (to that of Proposition 1, Fig. 4A) under Propositions 2 and 3. In Fig. 4B we trace out the impact of higher interconnectedness between the demand-side risk (viz., price-risk) and each of the two supply-side risks (viz., the background risk brought about by randomness in set-up costs, and the input price risk) on the decision of optimal input choice by the risk averse manufacturer. From Fig. 4B, it is established that with higher covariance/correlation between the random output prices and random set-up costs (the red locus), and with higher correlation between the random output and input prices (the blue locus), manufacturer will optimally opt for greater quantity of inputs (in both cases). This happens (for exactly opposite line of reasoning to that of Fig. 4A) if and only if preference follows both DARA $(a>1)$ and variance vulnerability $(b>2)$. 


\section{Comparison with the EU approach}

The first assumption made in Sect. 1 (page 3) is pertaining to the conformity of the locationscale conditions, so that all viable distributions vary only by location and scale parameters. We examine a choice set $Y$, where random variables $y \in Y$ differ only in terms of location and scale parameters. We consider $\boldsymbol{X}=\left(\widetilde{p_{x}}, \widetilde{p_{v}}, \tilde{Z}, \ldots, X_{n}\right)^{T}$ is a random vector with multivariate normal distribution and $X \in X$ is a random variable, obtained by normalisation of an arbitrary $y \in Y$. Hence, $X \sim \mathcal{N}(0,1)$, by construction.

Given the above, it follows that any $y \in Y$ is symmetrical in distribution to $\mu+\sigma x$, where $\mu$ and $\sigma$ are the mean and the standard deviation respectively. We denote $\boldsymbol{\Omega}=$ $\left\{\left(\sigma^{M}, \mu^{M}\right) \in \mathbb{R} \times \mathbb{R}_{+} \mid \exists y \in Y:(\sigma, \mu)=\left(\sigma^{M}, \mu^{M}\right)\right\}$ as the set of all possible $\left(\sigma^{M}, \mu^{M}\right)$ pairs that can be achieved for $y \in Y$. We assume $\boldsymbol{\Omega}$ is a convex set.

Given a von-Neumann Morgenstern (vNM) utility index $w: \mathbb{R} \rightarrow \mathbb{R}$, one can write the expected utility emanating from the distribution of $y$ using the mean and the standard deviation of $y$ (see Eichner \& Wagener, 2003, 2009, 2012; Mukherjee et al., 2021):

$$
E w(y)=\int_{a}^{b} w(\mu+\sigma x) d F(x) \equiv U(\sigma, \mu)
$$

where $F($.$) is a distribution function of X$. Identity (15) recommends structural relationships between functions $w$ and $U$. We assume that the regularity condition, imposed by Chipman (1973, Theorem 1), on $w($.$) holds, such that (15) holds for normal distribution. We$ utilise these relationships to demonstrate the comparative static results obtained in this paper have well-known correspondences in the EU framework.

Chipman (1973) shows that the fact that $X$ is normally distributed implies that

$$
\partial U(\sigma, \mu) / \partial \sigma=\sigma\left(\partial^{2} U(\sigma, \mu) / \partial \mu^{2}\right)<0
$$

Eichner and Wagener $(2003,2009)$ demonstrated that for strictly convex $(\sigma, \mu)$ indifference curve, variance vulnerability property is equivalent to stating that we have

$$
S(\sigma, \mu)-\sigma(\partial S(\sigma, \mu) / \partial \sigma)<0,
$$

Then, it is also equivalent to stating

$$
\begin{gathered}
-(\partial U(\sigma, \mu) / \partial \mu)\left[\partial U(\sigma, \mu) / \partial \sigma-\sigma\left(\partial^{2} U(\sigma, \mu) / \partial \sigma^{2}\right)\right] \\
-\sigma(\partial U(\sigma, \mu) / \partial \sigma)\left(\partial^{2} U(\sigma, \mu) / \partial \sigma \partial \mu\right)<0
\end{gathered}
$$

However, from (16), it is easy to follow that

$$
\left(\partial^{2} U(\sigma, \mu) / \partial \sigma^{2}\right)=\left(\partial^{2} U(\sigma, \mu) / \partial \mu^{2}\right)+\sigma\left(\partial^{3} U(\sigma, \mu) / \partial \mu^{2} \partial \sigma\right)
$$

Hence,

$$
\begin{aligned}
{\left[\partial U(\sigma, \mu) / \partial \sigma-\sigma\left(\partial^{2} U(\sigma, \mu) / \partial \sigma^{2}\right)\right] } & =-\sigma^{2}\left(\partial^{3} U(\sigma, \mu) / \partial \mu^{2} \partial \sigma\right) \\
& =-\sigma^{3}\left(\partial^{4} U(\sigma, \mu) / \partial \mu^{4}\right)
\end{aligned}
$$

Given that $\partial^{2} U(\sigma, \mu) / \partial \sigma \partial \mu>0,(\partial U(\sigma, \mu) / \partial \mu)>0$, but $(\partial U(\sigma, \mu) / \partial \sigma)<$ 0 , for a strictly quasi-concave mean - standard deviation utility function to exhibit risk aversion (Meyer, 1987); the inequality in (18) holds if and only if $\left[\partial U(\sigma, \mu) / \partial \sigma-\sigma\left(\partial^{2} U(\sigma, \mu) / \partial \sigma^{2}\right)\right]>0$ holds. Therefore, it is implied from (19) that $\left(\partial^{4} U(\sigma, \mu) / \partial \mu^{4}\right)<0$ turns out to be necessary and sufficient for (18) to hold. 
However, as demonstrated in Eeckhoudt et al. (1996), this condition, which is tantamount to absolute temperance, i.e., $w^{\prime \prime \prime \prime}()<$.0 , is one of the necessary conditions in the EU framework to induce decision-maker to reduce her risk-taking when independent background risk accentuates (in some specific manner). As expected, this property is also relevant for our more general dependence structures between output price risk, input price risk and background risk.

Eichner and Wagener (2009, Proposition 3) suggest $\varepsilon_{\sigma}>1-\beta$ is identical to the condition that index of relative prudence is smaller than $\beta$ in the EU-framework. Hence, assigning $\beta=1$ and 2 respectively, we obtain the sufficiency conditions $\varepsilon_{\sigma}>0$ and $\varepsilon_{\sigma}>-1$ respectively, which correspond to the outcomes obtained by Hadar and Seo (1990) for the case of independent risks and by Meyer and Ormiston (1994) for interconnected risks.

\section{Concluding remarks, policy implications and future directions}

Supply chains are invariably associated with multiple risks. However, literature reports these risks either of the supply side, demand side, or background risk using EU approach. A pragmatic view at SCs suggests that these risks are interconnected. Therefore, there is a glaring need to analyse the decision makers perspective considering this interconnectedness (Fan \& Stevenson, 2018). Sourcing contributes to $50 \%$ to $80 \%$ of the SC cost. Therefore, sourcing decision is vital to smooth functioning of the SC. Specifically when the decision maker is risk averse in his sourcing decision under the presence of interconnected risks.

This study aims to inquire the sourcing decision of a risk averse manufacturer cum seller. To contextualize this study, a generic drug manufacturer cum seller has been considered which operates in a regulatory product market like other commodity markets (e.g., petrol, gold, and other minerals). The need is to arrive at the optimal input choice for manufacturing under two supply-side risks: namely uncertain input costs as direct/endogenous risk, and uncertainty in set-up costs as an interconnected background risk. Later, we further extended the model with randomness in output prices as well, reflecting the uncertainty from demand side, on the top of two pre-existing supply-side risks. In such framework, we have evaluated the risk averse manufacturer's optimum supply decision in response to the changes in the interconnectivity (represented by covariance in the manufacturer's ex-post profit function with linear interactions among the decision variable and the normally distributed random variables) among each pair of these three sources of uncertainty, keeping all other parameters and individual standard deviations unchanged.

The complexity of a SC network is not only jerked by the size of the network but also interconnectivity among them. Thus, this study helps in understanding the optimal sourcing decision of a risk averse decision-maker with respect to the strength of interconnected risks in a SC network and demonstrates that with the increase in the strength of interconnectedness, the optimal souring of input material decreases. This finding will be helpful for the policymakers those anticipate the complexity is only because of the size of the network but this study extends this to strength of the interconnected network is also needs to be considered.

The comparative static responses are contingent upon the relative trade-offs between risks and returns i.e., the changes in the marginal willingness to sell for changes in the ex-post profit risk brought about by the changes in the covariance between any pair of risks.

Proposition 1 attempts to answer the first RQ by analysing the decision-making process in terms of optimum input choices of the risk averse manufacturer against the changes in the interconnectedness (covariance) between input price risk and random set-up costs, keeping 
all the parameters (including the individual standard deviations) unchanged. Proposition 1 suggests that when the input price risk is tightly coupled with the background risk, the risk averse decision-maker will optimally choose lesser quantity of inputs, if and only if the relative risk-taking of the manufacturer does not deteriorate too strongly due to increase in risk. This sufficiency condition is guaranteed by the positive values for the elasticity of risk aversion w.r.t. the changes in profit-risk.

Propositions 2 and 3 demonstrate the decision-making process of the risk averse manufacturer against the changes in interconnectedness between (i) random output price and background risk; and (ii) between random output price and random input price, keeping all other parameters unchanged. The results of these analyses suggest that (i) when the random output prices become tightly coupled with the background risk, and (ii) when the random output prices become more tightly coupled with input prices, manufacturer will optimally opt for greater quantity of inputs (in both cases), if and only if risk preference follows "properness" (satisfying both DARA and variance vulnerability). This is guaranteed by the ranges of values for the elasticity of risk aversion w.r.t. changes in profit-risk being greater than -1 and greater than 0 respectively for Propositions 2 and 3. In this manner, we provide answers to RQ 2 and RQ 3 respectively.

The piety of the mean-variance decision model lies in its simplicity of interpretability-the sufficiency conditions are based on the manufacturer's relative sensitivity towards risks. These conditions are more liable as empirically testable predictions; in contrast to the alternative (such as an expected utility) approaches, which otherwise would depend on higher-order derivatives of utility functions and their composites.

In terms of policy recommendations, our analysis confirms that degree of interconnectedness among SC risks impact risk averse manufacturers' input choice decisions. This is important for policy makers to keep in mind when designing market rules for regulated products. Policy makers should try to reduce at least one side of risk so that manufacturer can increase his sourcing inputs. Policymakers can provide fixed subsidy or incentive so that supply side or background risk can be reduced. For the demand side proper forecasting about the market demand venturing into new markets which are risk free because of government regulations can be another option for the manufacturer to improve its optimal sourcing strategy. However, risk averse manufacturer under tightly coupled risks can take the recourse of inventory management, multi-sourcing and hedging as alternative strategies to reduce the supply side risk through which background risk and demand side risk can also be managed by establishing loosely coupled supply chain risks.

The present work can be extended to several imperative directions. The most exciting extension would be to apply this precise decision problem in the context of loss-aversion or disappointment aversion. Consideration of multiplicative risks to analyse Complex SC network can also be another extension. Data collection using behavioural experiments to study the risk averse behaviour can also be considered as future scope. Also, different product markets with different regulations can be considered in future research.

Acknowledgements The authors are grateful to the guest editors (Prof. (Dr) Jean-Luc Prigent, Prof. (Dr) Ephraim Clark, and Prof. (Dr) Giovanni Barone Adesi) and two anonymous referees for their constructive comments on its submitted version of December 2019. The authors are also grateful to Prof. (Dr) Stephen M. Wagner (ETH Zurich) and Prof. (Dr) Udo Broll (TU Dresden) for their inputs on another past version of this research, which had been drafted as a CREDIT WP version [Mukherjee, S. \& Padhi, S.S. (2018). Risk Connectivity and Risk Mitigation: An Analytical Framework, CREDIT WP Series No. 18/11, University of Nottingham (UK). Available at: <https://www.nottingham.ac.uk/credit/documents/papers/2018/18-11.pdf >]. Both the submitted version of December 2019 and this present revision are substantially different from the above-mentioned draft. The usual disclaimers are applicable. 
Open Access This article is licensed under a Creative Commons Attribution 4.0 International License, which permits use, sharing, adaptation, distribution and reproduction in any medium or format, as long as you give appropriate credit to the original author(s) and the source, provide a link to the Creative Commons licence, and indicate if changes were made. The images or other third party material in this article are included in the article's Creative Commons licence, unless indicated otherwise in a credit line to the material. If material is not included in the article's Creative Commons licence and your intended use is not permitted by statutory regulation or exceeds the permitted use, you will need to obtain permission directly from the copyright holder. To view a copy of this licence, visit http://creativecommons.org/licenses/by/4.0/.

\section{References}

Alghalith, M., Niu, C., \& Wong, W. K. (2017). The impacts of joint energy and output prices uncertainties in a mean-variance framework. Theoretical Economics Letters, 7, 1108-1120.

Babich, V., Burnetas, A. N., \& Ritchken, P. H. (2007). Competition and diversification effects in supply chains with supplier default risk. Manufacturing and Service Operations Management, 9(2), 123-146.

Baldwin, C. Y., Clark, K. B., \& Clark, K. B. (2000). Design rules: The power of modularity (Vol. 1). Cambridge: MIT press.

Bluhm, M., \& Krahnen, J. P. (2014). Systemic risk in an interconnected banking system with endogenous asset markets. Journal of Financial Stability, 13, 75-94.

Bode, C., \& Wagner, S. M. (2015). Structural drivers of upstream supply chain complexity and the frequency of supply chain disruptions. Journal of Operations Management, 36, 215-228.

Bombelli, A., Santos, B. F., \& Tavasszy, L. (2020). Analysis of the air cargo transport network using a complex network theory perspective. Transportation Research Part E: Logistics and Transportation Review, 138, 101959.

Broll, U., Guo, X., Welzel, P., \& Wong, W. K. (2015). The banking firm and risk taking in a two-moment decision model. Economic Modelling, 50, 275-280.

Broll, U., \& Mukherjee, S. (2017). International trade and firms' attitude towards risk. Economic Modelling, 64, 69-73.

Broll, U., Mukherjee, S., \& Sensarma, R. (2019). Risk preference estimation of exporting firm under exchange rate uncertainty. Scottish Journal of Political Economy. https://doi.org/10.1111/sjpe.12226

Cavallo, A., \& Ireland, V. (2014). Preparing for complex interdependent risks: A System of Systems approach to building disaster resilience. International Journal of Disaster Risk Reduction, 9, 181-193.

Chamberlain, G. (1983). A characterization of the distributions that imply mean-Variance utility functions. Journal of Economic Theory, 29(1), 185-201.

Chipman, J. S. (1973). The ordering of portfolios in terms of mean and variance. The Review of Economic Studies, 40(2), 167-190.

Chopra, S., \& Sodhi, M. S. (2004). Supply-chain breakdown. MIT Sloan Management Review, 46(1), 53-61.

Christopher, M., \& Peck, H. (2004). Building the Resilient Supply Chain. International Journal of Logistics Management, 15(2), 1-13.

Chung, K. H. (1990). Output decision under demand uncertainty with stochastic production function: a contingent claims approach. Management Science, 36(11), 1311-1328.

Correa-Henao, G. J., Yusta, J. M., \& Lacal-Arántegui, R. (2013). Using interconnected risk maps to assess the threats faced by electricity infrastructures. International Journal of Critical Infrastructure Protection, 6(3-4), 197-216.

Earnest, D. C., \& Wilkinson, I. F. (2018). An agent based model of the evolution of supplier networks. Computational and Mathematical Organization Theory, 24(1), 112-144.

Eeckhoudt, L., Gollier, C. C., \& Schlesinger, H. (1996). Changes in Background Risk and Risk Taking Behavior. Econometrica, 64(3), 683-689.

Eichner, T. (2008). Mean variance vulnerability. Management Science, 54(3), 586-593.

Eichner, T., \& Wagener, A. (2003). Variance vulnerability, background risks, and mean-variance preferences. The Geneva Papers on Risk and Insurance Theory, 28(2), 173-184.

Eichner, T., \& Wagener, A. (2005). Measures of risk attitude: Correspondences between mean-variance and expected-utility approaches. Decisions in Economics and Finance, 28, 53-65.

Eichner, T., \& Wagener, A. (2009). Multiple risks and mean-variance preferences. Operations Research, 57(5), 1142-1154.

Eichner, T., \& Wagener, A. (2012). Tempering effects of (dependent) background risks: A mean-variance analysis of portfolio selection. Journal of Mathematical Economics, 48(6), 422-430. 
Elkins, D., Handfield, R. B., Blackhurst, J., \& Craighead, C. W. (2005). 18 ways to guard against disruption. Supply Chain Management Review, 9(1), 46-52.

Embrechts, P., McNeil, A., \& Straumann, D. (2002). Correlation and dependence in risk management: Properties and pitfalls. Risk Management: Value at Risk and beyond, 1, 176-223.

Fahimnia, B., Pournader, M., Siemsen, E., Bendoly, E., \& Wang, C. (2019). Behavioral operations and supply chain management-a review and literature mapping. Decision Sciences, 50, 1127-1183. https://doi.org/ 10.1111/deci.12369.

Faisal, M. N. (2009). Prioritization of risks in supply chains. In: Managing supply chain risk and vulnerability. Springer, London. pp 41-66

Fan, Y., \& Stevenson, M. (2018). A review of supply chain risk management: Definition, theory, and research agenda. International Journal of Physical Distribution \&amp; Logistics Management, 48(3), 205-230.

Fischl, M., Scherrer-Rathje, M., \& Friedli, T. (2014). Digging deeper into supply risk: A systematic literature review on price risks. Supply Chain Management: An International Journal, 19(5/6), 480-503.

Giannakis, M., \& Papadopoulos, T. (2016). Supply chain sustainability: A risk management approach. International Journal of Production Economics, 171, 455-470.

Govindan, K., Fattahi, M., \& Keyvanshokooh, E. (2017). Supply chain network design under uncertainty: A comprehensive review and future research directions. European Journal of Operational Research, 263(1), 108-141.

Guertler, B., \& Spinler, S. (2015). When does operational risk cause supply chain enterprises to tip? A simulation of intra-organizational dynamics. Omega, 57, 54-69.

Guo, X., Egozcue, M., \& Wong, W. K. (2021). Production theory under price uncertainty for firms with disappointment aversion. International Journal of Production Research, 59(8), 2392-2405.

Hachicha, W., \& Elmsalmi, M. (2014). An integrated approach based-structural modelling for risk prioritization in supply network management. Journal of Risk Research, 17(10), 1301-1324.

Hadar, J., \& Seo, T. (1990). The effects of shifts in a return distribution on optimal portfolios. International Economic Review, 31(3), 721-736.

Han, W. M., \& Huang, S. J. (2007). An empirical analysis of risk components and performance on software projects. Journal of Systems and Software, 80(1), 42-50.

Harland, C. (2021). Discontinuous wefts: Weaving a more interconnected supply chain management tapestry. Journal of Supply Chain Management, 57(1), 27-40.

Hearnshaw, E. J. S., \& Wilson, M. M. J. (2013). A complex network approach to supply chain network theory. International Journal of Operations \&amp; Production Management, 33(4), 442-469.

Heckmann, I., Comes, T., \& Nickel, S. (2015). A critical review on supply chain risk-Definition, measure and modeling. Omega, 52, 119-132.

Hendricks, K. B., \& Singhal, V. R. (2005). An empirical analysis of the effect of supply chain disruptions on long-run stock price performance and equity risk of the firm. Production and Operations Management, 14(1), 35-52.

Ho, W., Zheng, T., Yildiz, H., \& Talluri, S. (2015). Supply chain risk management: A literature review. International Journal of Production Research, 53(16), 5031-5069.

Hong, Z., \& Lee, C. K. M. (2013). A decision support system for procurement risk management in the presence of spot market. Decision Support Systems, 55(1), 67-78.

Huang, X., \& Jiang, G. (2020). Portfolio management with background risk under uncertain mean-variance utility. Fuzzy Optimization and Decision Making.

Ivanov, D. (2018). Revealing interfaces of supply chain resilience and sustainability: A simulation study. International Journal of Production Research, 56(10), 3507-3523.

Jüttner, U., Peck, H., \& Christopher, M. (2003). Supply chain risk management: Outlining an agenda for future research. International Journal of Logistics: Research and Applications, 6(4), 197-210.

Kayis, B., \& Dana Karningsih, P. (2012). SCRIS: A knowledge-based system tool for assisting manufacturing organizations in identifying supply chain risks. Journal of Manufacturing Technology Management, 23(7), 834-852.

Kazaz, B., \& Webster, S. (2015). Technical Note-Price-Setting Newsvendor Problems with Uncertain Supply and Risk Aversion. Operations Research, 63(4), 807-811.

Kleindorfer, P. R., \& Saad, G. H. (2005). Managing disruption risks in supply chains. Production and Operations Management, 14(1), 53-68.

Kumbhakar, S. C., \& Tsionas, E. G. (2010). Estimation of production risk and risk preference function: A nonparametric approach. Annals of Operations Research, 176(1), 369-378. https://doi.org/10.1007/ s10479-008-0472-5

Ledwoch, A., Brintrup, A., Mehnen, J., \& Tiwari, A. (2016). Systemic risk assessment in complex supply networks. IEEE Systems Journal, 12(2), 1826-1837.

Li, X., \& Qi, X. (2021). On pricing and quality decisions with risk aversion. Omega, 98, 102118. 
Liu, Z., \& Cruz, J. M. (2012). Supply chain networks with corporate financial risks and trade credits under economic uncertainty. International Journal of Production Economics, 137(1), 55-67.

McNerney, J., Farmer, J. D., Redner, S., \& Trancik, J. E. (2011). Role of design complexity in technology improvement. Proceedings of the National Academy of Sciences, 108(22), 9008-9013.

Meyer, J. (1987). Two-moment decision models and expected utility maximization. The American Economic Review, 421-430.

Meyer, J. (2010). Representing risk preferences in expected utility based decision models. Annals of Operations Research, 176(1), 179-190. https://doi.org/10.1007/s10479-008-0381-7

Meyer, J., \& Ormiston, M. (1994). The effect on optimal portfolios of changing the return to a risky asset: The case of dependent risky returns. International Economic Review, 35(3), 603-612.

Mezei, J., \& Sarlin, P. (2018). RiskRank: Measuring interconnected risk. Economic Modelling, 68, 41-50.

Mizgier, K. J., Jüttner, M. P., \& Wagner, S. M. (2013). Bottleneck identification in supply chain networks. International Journal of Production Research, 51(5), 1477-1490.

Mukherjee, S., Mukherjee, S., Mishra, T. K., Broll, U., \& Parhi, M. (2021). Spot exchange rate volatility, uncertain policies and export investment decision of firms: a mean-variance decision approach. The European Journal of Finance, 27(8), 752-773. https://doi.org/10.1080/1351847X.2020.1842785

Owen, J., \& Rabinovitch, R. (1983). On the class of elliptical distributions and their applications to the theory of portfolio choice. The Journal of Finance, 38(3), 745-752.

Padhi, S. S., \& Mukherjee, S. (2021). Optimal portfolio choices to split orders during supply disruptions: An application of sport's principle for routine sourcing. Decision Sciences. https://doi.org/10.1111/deci. 12511

Peck, H. (2006). Reconciling supply chain vulnerability, risk and supply chain management. International Journal of Logistics: Research and Applications, 9(2), 127-142.

Pescaroli, G., \& Alexander, D. (2018). Understanding compound, interconnected, interacting, and cascading risks: A holistic framework. Risk Analysis, 38(11), 2245-2257.

Pettit, T. J., Croxton, K. L., \& Fiksel, J. (2013). Ensuring supply chain resilience: Development and implementation of an assessment tool. Journal of Business Logistics, 34(1), 46-76.

Phillips, M. A., \& Ritala, P. (2019). A complex adaptive systems agenda for ecosystem research methodology. Technological Forecasting and Social Change, 148, 119739.

Pournader, M., Kach, A., \& Talluri, S. (2020). A review of the existing and emerging topics in the supply chain risk management literature. Decision Sciences, 51(4), 867-919.

Ritchie, B., \& Brindley, C. (2007). An emergent framework for supply chain risk management and performance measurement. Journal of the Operational Research Society, 58(11), 1398-1411.

Rodríguez-Puerta, I., \& Álvarez-López, A. A. (2016). Optimal allocation of a fixed production under price uncertainty. Annals of Operations Research, 237(1-2), 121-142. https://doi.org/10.1007/s10479-0141702-7

Saha, A. (1997). Risk preference estimation in the nonlinear mean standard deviation approach. Economic Inquiry, 35(4), 770-782.

Samvedi, A., Jain, V., \& Chan, F. T. S. (2013). Quantifying risks in a supply chain through integration of fuzzy AHP and fuzzy TOPSIS. International Journal of Production Research, 51(8), 2433-2442.

Sandmo, A. (1971). On the theory of the competitive firm under price uncertainty. The American Economic Review, 61(1), 65-73. Retrieved July 21, 2021, from http://www.jstor.org/stable/1910541.

Shahbaz, M. S., Qureshi, M. A., Sohu, S., \& Keerio, M. A. (2020). The impacts of operational risks in the supply chain of construction projects in Malaysia. Tehnicki Vjesnik-Technical Gazette, 27(6), 1887-1894.

Sheffi, Y. (2007). The resilient enterprise - overcoming vulnerability for competitive advantage. USA: MIT Press.

Shekarian, M., \& Mellat Parast, M. (2020). An Integrative approach to supply chain disruption risk and resilience management: a literature review. International Journal of Logistics Research and Applications, $1-29$.

Shen, S. (2013). Optimizing designs and operations of a single network or multiple interdependent infrastructures under stochastic arc disruption. Computers \&amp; Operations Research, 40(11), 2677-2688.

Skilton, P. F., \& Robinson, J. L. (2009). Traceability and normal accident theory: how does supply network complexity influence the traceability of adverse events? Journal of Supply Chain Management, 45(3), 40-53.

Sodhi, M. S., Son, B. G., \& Tang, C. S. (2012). Researchers' perspectives on supply chain risk management. Production and Operations Management, 21(1), 1-13.

Supply Chain Risk Managemet Council. (2011). Supply chain risk management: A compilation of best practices. Unpublished document. Accessed at: <http://www.scrlc.com/articles/Supply_Chain_Risk_ Management_A_Compilation_of_Best_Practices_final[1].pdf $>$. 
Sweetman, R., \& Conboy, K. (2018). Portfolios of agile projects: A complex adaptive systems' agent perspective. Project Management Journal, 49(6), 18-38.

Tang, O., \& Musa, S. N. (2011). Identifying risk issues and research advancements in supply chain risk management. International Journal of Production Economics, 133(1), 25-34.

Thun, J. H., \& Hoenig, D. (2011). An empirical analysis of supply chain risk management in the German automotive industry. International Journal of Production Economics, 131(1), 242-249.

Turner, R. W. (2011). Supply management and procurement: from the basics to best-in-class. J. Ross Publishing.

Venkatesh, V. G., Rathi, S., \& Patwa, S. (2015). Analysis on supply chain risks in Indian apparel retail chains and proposal of risk prioritization model using Interpretive structural modeling. Journal of Retailing and Consumer Services, 26, 153-167.

Vespignani, A. (2010). The fragility of interdependency: A study of failures in interconnected networks highlights the vulnerability of tightly coupled infrastructures and shows the need to consider mutually dependent network properties in designing resilient systems. Nature, 464(7291), 984+. https://www.link.gale. com/apps/doc/A224520292/AONEu=tacoma_comm\&sid=googleScholar\&xid=8c938270. Accessed 25 May 2021.

Wagner, S. M., \& Bode, C. (2009). Dominant risks and risk management practices in supply chains. In: Supply chain risk (pp. 271-290). Springer, Boston, MA.

Wagner, S. M., \& Bode, C. (2006). An empirical investigation into supply chain vulnerability. Journal of Purchasing and Supply Management, 12(6), 301-312.

Wagner, S. M., Bode, C., \& Koziol, P. (2009). Supplier default dependencies: Empirical evidence from the automotive industry. European Journal of Operational Research, 199(1), 150-161.

Wagner, S. M., Mizgier, K. J., \& Arnez, P. (2014). Disruptions in tightly coupled supply chain networks: The case of the US offshore oil industry. Production Planning \&amp; Control, 25(6), 494-508.

Wallace, L., Keil, M., \& Rai, A. (2004). Understanding software project risk: A cluster analysis. Information \&amp; Management, 42(1), 115-125.

Waters, D. (2011). Supply chain risk management: vulnerability and resilience in logistics. Kogan Page Publishers.

Zuccaro, G., De Gregorio, D., \& Leone, M. F. (2018). Theoretical model for cascading effects analyses. International Journal of Disaster Risk Reduction, 30, 199-215.

Publisher's Note Springer Nature remains neutral with regard to jurisdictional claims in published maps and institutional affiliations. 